\title{
Ageing and the border between health and disease
}

\author{
William MacNee, Roberto A. Rabinovich and Gourab Choudhury \\ Number 3 in the series "Multimorbidity and the lung" \\ Edited by L.M. Fabbri and J.M. Drazen
}

Affiliation: ELEGI Colt Research Laboratories, MRC Centre for Inflammation Research, University of Edinburgh, Edinburgh, UK.

Correspondence: William MacNee, ELEGI Colt Research Laboratories, MRC Centre for Inflammation Research, Queen's Medical Research Institute, University of Edinburgh, 47 Little France Crescent, Edinburgh, EH16 4TJ, UK. E-mail: w.macneeded.ac.uk

ABSTRACT Ageing is associated with a progressive degeneration of the tissues, which has a negative impact on the structure and function of vital organs and is among the most important known risk factors for most chronic diseases. Since the proportion of the world's population aged $>60$ years will double in the next four decades, this will be accompanied by an increased incidence of chronic age-related diseases that will place a huge burden on healthcare resources.

There is increasing evidence that many chronic inflammatory diseases represent an acceleration of the ageing process. Chronic pulmonary diseases represents an important component of the increasingly prevalent multiple chronic debilitating diseases, which are a major cause of morbidity and mortality, particularly in the elderly. The lungs age and it has been suggested that chronic obstructive pulmonary disease (COPD) is a condition of accelerated lung ageing and that ageing may provide a mechanistic link between COPD and many of its extrapulmonary effects and comorbidities. In this article we will describe the physiological changes and mechanisms of ageing, with particular focus on the pulmonary effects of ageing and how these may be relevant to the development of COPD and its major extrapulmonary manifestations.

0 @ERSpublications

Premature ageing of the lung may constitute pathogenetic mechanisms contributing to COPD http://ow.ly/BGd52

Previous articles in this series. No. 1: Faner R, Cruz T, López-Giraldo A, et al. Network medicine, multimorbidity and the lung in the elderly. Eur Respir J 2014; 44: 775-788. No. 2: Divo MJ, Martinez CH, Mannino DM. Ageing and the epidemiology of multimorbidity. Eur Respir J 2014; 44: 1055-1068.

Received: July 232014 | Accepted after revision: Sept 222014 | First published online: Oct 162014

Conflict of interest: Disclosures can be found alongside the online version of this article at erj.ersjournals.com

Copyright @ERS 2014 


\section{Introduction}

Ageing is characterised by a progressive degeneration of the tissues that has a negative impact on the structure and function of vital organs [1]. Loss of physiological integrity, resulting in a progressive decline of homeostasis and reduced capacity to respond to environmental stimuli with age, contributes to an incremental risk of disease and death. The age demographic of the world's population is changing. According to the World Health Organization, "Between 2000 and 2050, the proportion of the world's population over the age of 60 years will double from around $11 \%$ to $22 \%$. The absolute number of people aged over 60 years is expected to increase from 605 million to 2 billion over the same period" [2]. This poses a challenge to society in the years to come and, in particular, there will be an incremental need for healthcare for chronic diseases in the more fragile portion of the population.

Ageing is among the most important known risk factors for most chronic diseases [3, 4] (fig. 1). Around 100000 people worldwide die each day of age-related causes [5].

The number of changes in the body that occur with age is remarkably long and include changes in appearance, such as wrinkled skin, gradual reduction in height and weight loss due to loss of muscle and bone mass, decline in sexual activity (and menopause in women), and decline in the function of most organs such as renal, pulmonary, cardiac and cerebral. Immune and endocrine functions are also affected [6]. It has been suggested that ageing results from a range of intrinsic phenomena that affect the whole organism and consequently leads to the "weakest link" organ failing, culminating in death. However, the ageing process does not share its core features with any particular disease and, as suggested by HAYFLICK [7], it is not a disease in itself, but increases vulnerability to disease. All organs tend to lose function with age and this is well described in the lung where there is a progressive decline in lung function after the age of 25 years. Chronic obstructive pulmonary disease (COPD) represents an important component of the increasingly prevalent multiple chronic debilitating disease epidemic that becomes more prevalent with age and is a major cause of morbidity and mortality [8]. There is increasing evidence that chronic inflammatory conditions such as COPD represent an acceleration of the ageing process [9].

In this article we will describe the physiological changes associated with ageing and the proposed mechanisms of ageing. We will then focus on the pulmonary effects of ageing and how these may be relevant to the development of the chronic lung disease; COPD and the role of ageing in the multimorbidities associated with COPD.

\section{Physiological changes and mechanisms of ageing}

Three groups of physiological changes associated with age have been defined [10]: 1) changes in cellular homeostasis mechanisms (body temperature, blood and extracellular fluid volumes); 2) decrease in organ mass; and 3) decline in and loss of the functional reserve of the body. Age-associated changes are largely determined by genetics and are influenced by environmental factors (diet, exercise, exposure to microorganisms, cigarette smoke, air pollutants and ionising radiation). Other factors can also influence the ability to live longer. Longevity differs between sexes, with females living 7-10 years longer than males [11]. Childhood, personality, education and behavioural factors also contribute to longevity [12].

There are a number of cellular and molecular mechanisms that are thought to be involved in the ageing process and determine the ageing phenotype (fig. 2). These mechanisms will be discussed later in this article; however a detailed discussion of all of these mechanisms is provided elsewhere [13].

FIGURE 1 Prevalence of selected chronic conditions as a function of age. COPD: chronic obstructive pulmonary disease. Reproduced from [5] with permission from the publisher.

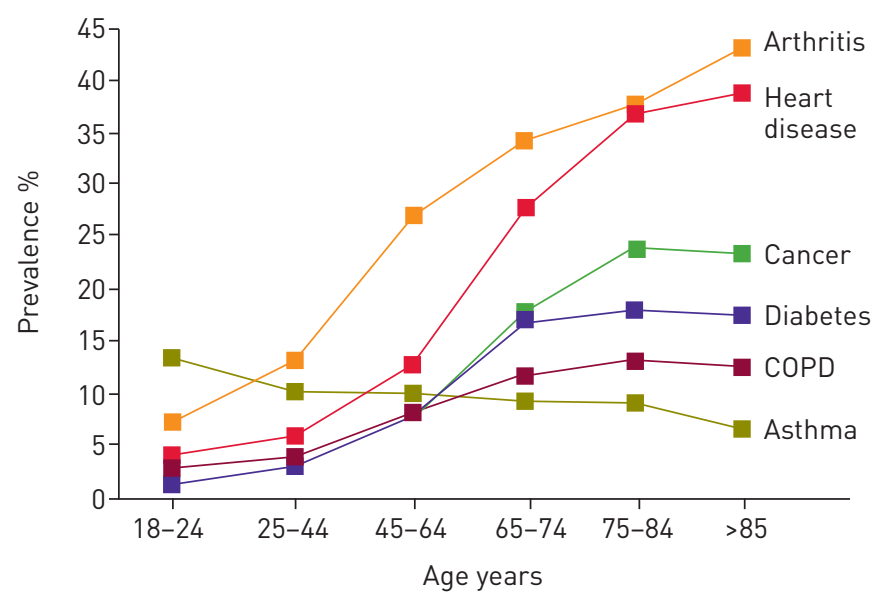


In general, ageing is determined by the interaction between injury and repair, and the balance between cell death and cell replacement in order to maintain organ integrity [14-16].

If cells die faster than they can be replaced, the remaining cells need to respond to greater demands that can eventually lead to pathological changes and deterioration in cell health. Intrinsic and extrinsic factors that modify the balance between cell death and replacement have considerable impact on the ageing process. Cell division and programmed cell death (apoptosis) are regulated by genetic factors and subject to extra- and intracellular molecular factors.

One common factor underlying the process of ageing is the accumulation of molecular damage. Therefore, ageing may be considered to result from the accumulation of cellular damage, consequent changes in gene expression and epigenetic factors related to DNA damage, and structural modifications of the DNA by the intrinsic biological clock that regulates the number of cell divisions, such as telomere shortening [17]. Thus, ageing is influenced by the interaction of genetic and environmental factors. Two of the main theories of ageing are the free radical theory and the replicative senescence theory.

\section{Free radical theory of ageing}

According to the endosymbiotic theory articulated in 1910 by the Russian botanist MERESCHOWSKI [18] and advanced later in 1967 by SAGAN [19], the mitochondria were once free-living prokaryotic cells, following the evolution of aerobic metabolism, and were acquired symbiotically by protozoans to form eukaryotic cells. Whether this theory is true or not, the presence of the mitochondria in the cytosol has remarkable implications for the production of energy by eukaryotic cells. However, there is a downside to this arrangement [20]. Although the mitochondrial production of energy (ATP) through oxidative phosphorylation is efficient, a small percentage of electrons may "leak" during normal respiration and prematurely reduce oxygen, forming reactive oxygen species (ROS) [21]. As cells and organisms age, the function of the mitochondria tends to diminish, thus increasing electron leakage that in turn increases the production of ROS. ROS are highly unstable and can interact with lipids, proteins and nucleic acid, thus damaging vital cell components, including further damage to mitochondria. This is the basis of the free radical theory of ageing, originally proposed in 1956 by HARMAN [22], which focuses on the mitochondria as an increasing source of free radicals with ageing. However, age-associated mitochondrial dysfunction can contribute to ageing independent of ROS as a result of aberrant mitochondrial biogenesis, caused by impaired retrograde signalling that is regulated by nuclear genes and factors dependent on mitochondrial metabolism [23].

The free radical/mitochondrial theory of ageing proposed that ageing results from accumulated damage inflicted by ROS [24]. However, this simplistic view has been challenged [25, 26]. Evidence is accumulating that an optimal amount of ROS are required for successful ageing, which can trigger proliferative and survival signals in response to physiological and stress signals [27]. Thus, with ageing, the levels of ROS increase in an attempt to maintain survival [28] until they reach a level where they enhance, rather than alleviate, age-related damage [29]. ROS can also be formed by exogenous processes such as irradiation, environmental pollutants and inflammation, as well as normal cell metabolism. Free radicals can: accelerate replicative senescence via the shortening of telomeres; activate inflammatory redox-sensitive transcription

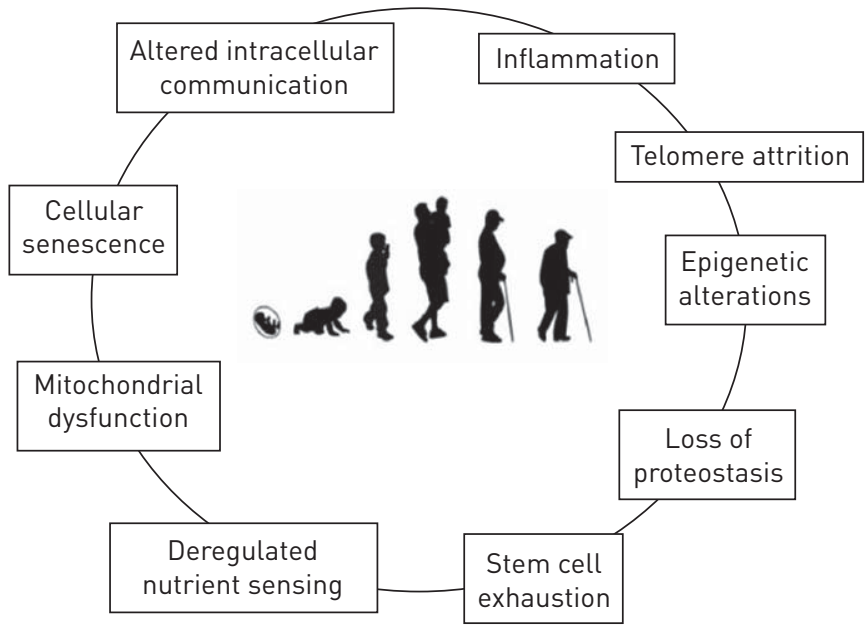

FIGURE 2 The processes associated with ageing. Reproduced and modified from [13] with permission from the publisher. 
factors such as nuclear factor- $\kappa \mathrm{B}(\mathrm{NF}-\kappa \mathrm{B})$ and activator protein-1, which regulate the transcription of several genes encoding pro-inflammatory cytokines; and induce DNA damage [30].

Chronic inflammation, characterised by higher levels of pro-inflammatory cytokines and the infiltration of inflammatory cells into tissues, is a feature of ageing and most age-related diseases including COPD, cardiovascular disease, osteoporosis, rheumatoid arthritis, cataract and Alzheimer's disease [31].

\section{Replicative senescence theory of ageing}

The other major theory of ageing is the replicative senescence theory $[32,33]$. This is based on the fact that with every cell division there is incomplete duplication of the telomeres. Telomeres are regions at the ends of chromosomes containing $1-5 \mathrm{~kb}$ of (TTAGGG) repeats that protect DNA against degradation and recombination, thus supporting chromosomal stability [34]. In most somatic cells telomeres shorten with every cell cycle since replicative DNA polymerases lack the capacity to completely replicate the terminal ends of linear DNA molecules, which is a property of the specialised DNA polymerase known as telomerase. However, most mammalian somatic cells do not express telomerase and this leads to progressive loss of telomere protective sequences from the ends of chromosomes. Therefore, telomere length reflects the length at birth and its rate of attrition thereafter. The latter is a result of the replication history, but is also a reflection of a number of factors, such as cumulative oxidative stress and chronic inflammation, acting on progenitor cells [33]. Successive cell divisions result in telomere shortening of chromosomes until cells are no longer capable of dividing. Therefore, the balance between cell death and cell replication is affected and defence, maintenance and repair of the body becomes increasingly impaired. Telomere length has been considered as a measure of biological rather than chronological age or, more recently, as a biomarker of somatic redundancy that is the body's capacity to absorb damage [35]. There is a strong relationship between short telomeres and the risk of mortality.

Recent studies have begun to unite the free radical and replicative senescence theories of ageing (fig. 3). In fact, shortened telomeres are associated with ageing and elevated oxidative damage. Shortened telomeres induce p53, which in turn suppress two gene products (the proliferator-activated receptor-gamma coactivator $-1 \alpha$ and $-\beta$ genes) whose expression is necessary for mitochondrial function and survival. This results in mitochondrial dysfunction with elevated free radical production, potentially resulting in the appearance of several age-associated diseases.

\section{Cellular senescence}

The cell responses to stress, such as ROS, are directed toward cell arrest or, if the damage is beyond repair, toward cell death. Cellular senescence is a process in which cellular stresses converge to promote cell cycle arrest, associated with stereotyped phenotypic changes [36]. In addition to replicative senescence, in which progressive telomere shortening leads to senescence [37], oxidative stress-induced DNA damage can similarly promote cell arrest; stress-induced premature senescence [38, 39].

There is a close relationship between cellular senescence and inflammation. Unlike apoptotic cells, senescence cells remain metabolically active and exhibit what is termed a "senescence-associated secretory phenotype" (SASP) [40]. Senescent cells demonstrate activation of NF- $\kappa B$, a major transcription factor in the regulation of inflammation. Senescent cells also release increased amounts of various inflammatory cytokines resulting in enhanced inflammation [41]. These pro-inflammatory mechanisms associated with senescence have been shown in human lung tissue, where the expression of phosphorylated inhibitor of

FIGURE 3 Interaction between the free radical and senescence theories of ageing.

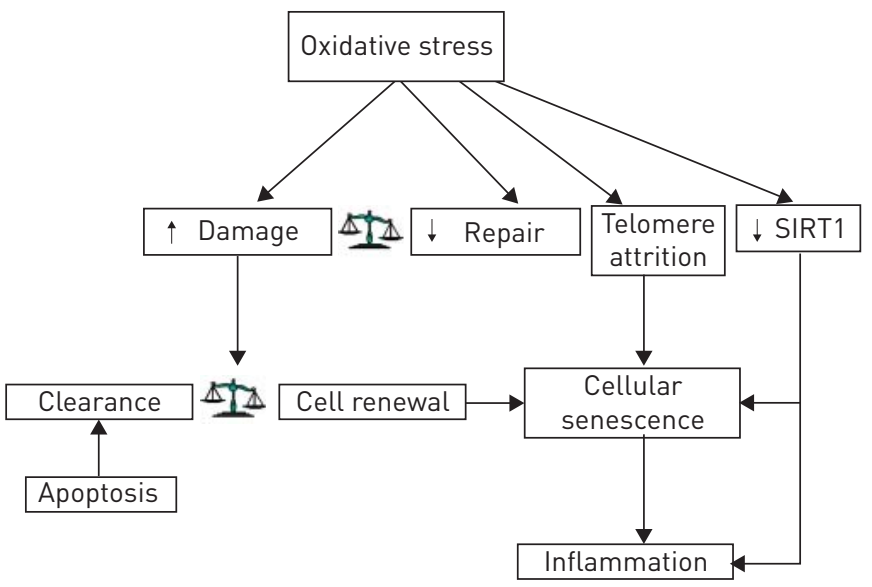


$\mathrm{NF}-\mathrm{kB}$ and tumour necrosis factor (TNF)- $\alpha$ were found to be increased in $\mathrm{p} 16^{\mathrm{INK} 4 \mathrm{a}}$-positive type II alveolar epithelial cells, a marker of cellular senescence, suggesting that senescent alveolar cells promote inflammation at the cellular level [42]. With advancing age, senescent cells accumulate in tissues resulting in SASP-elicited inflammation that is believed to influence the development of age-related conditions.

In youth, cellular senescence prevents the proliferation of damaged cells, thus protecting against cancer and contributing to homeostasis. With ageing, enhanced damage and deficient clearance and replenishment of senescent cells results in their accumulation and consequently a number of deleterious effects on tissue homeostasis that contribute to ageing (fig. 4).

\section{Epigenetic mechanisms in ageing}

A range of epigenetic mechanisms are involved in ageing. Epigenetic changes involve alterations in DNA methylation, post-translational modifications of histones and chromatin remodelling. The histone deacetylases (HDACs) sirtuin (Sir2 proteins) is involved in these epigenetic mechanisms and have been extensively studied as potential anti-ageing factors. Within the group of HDACs, sirtuin proteins maintain a special position as they are structurally different from other HDACs and are inhibited by different compounds since they have the unique characteristic of being $\mathrm{NAD}^{+}$-dependent [43]. Seven sirtuin homologues (SIRT1-SIRT7) are found in mammals [44]. Sirtuins are type III HDACs and act on histone residues in DNA that are essential for maintaining silent chromatin during histone deacetylation. SIRT6 and SIRT7 are localised in the nucleus, SIRT3, SIRT4 and SIRT5 are localised in the mitochondria while SIRT1 and SIRT2 are localised in the nucleus and distributed in the cytosol. These seven isoforms display differential specificity toward acetylated substrates, which translates into an expanding range of physiological functions, such as gene expression, cell cycle regulation, apoptosis and metabolism, as well as ageing.

Other so called anti-ageing molecules include HDAC2 [45] and a group of molecules responsible for DNA repair, such as DNA-dependent protein kinase and Ku86 [46]. The imbalance between pro- and anti-ageing molecules contributes to accelerate the molecular features responsible for the changes associated with ageing.

\section{Loss of proteostasis}

Ageing and some age-related diseases have been linked to impaired protein homeostasis or proteostasis [47]. Proteostasis includes a range of processes by which cells stabilise correctly folded proteins or restore or

a)

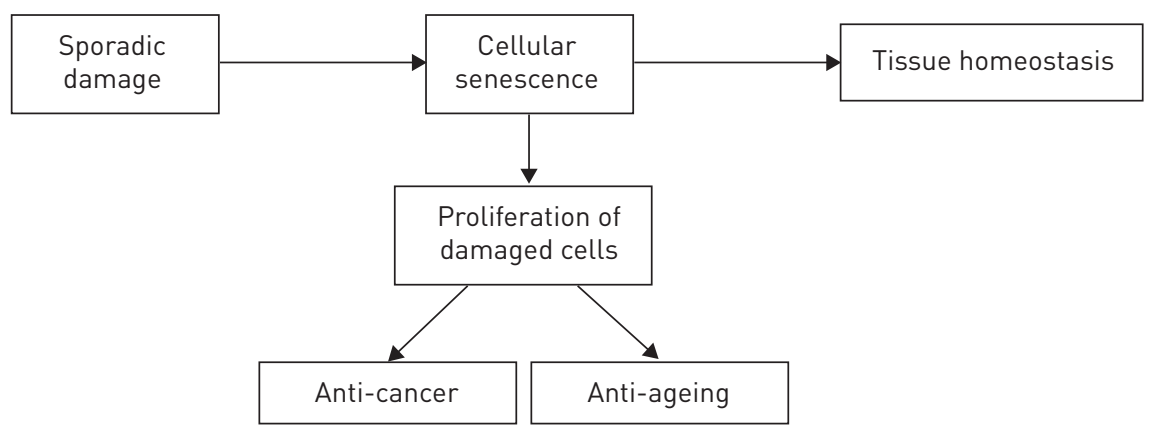

b)

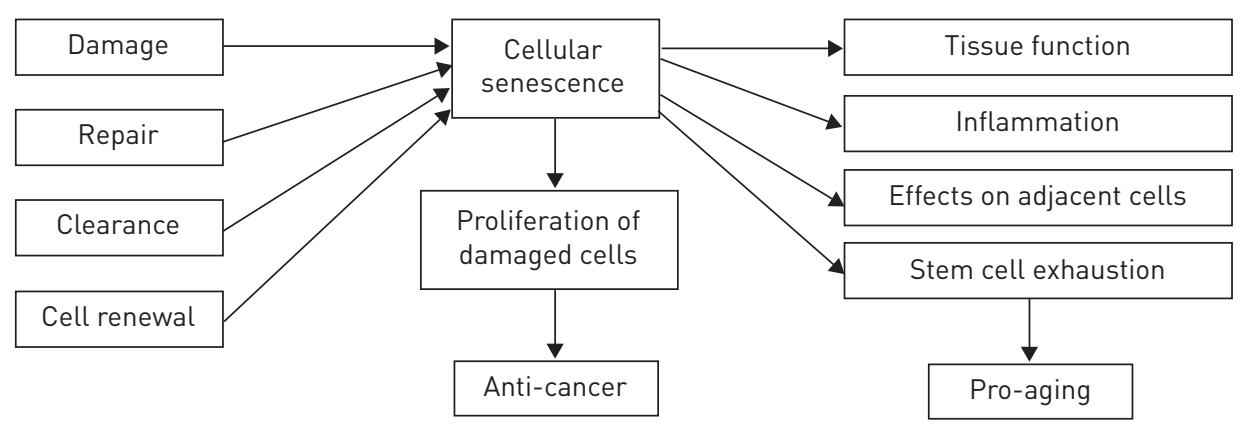

FIGURE 4 Cellular senescence. a) In youth, cellular senescence prevents the proliferation of damaged cells, thus protecting them from cancer and contributing to tissue homeostasis. b) With ageing, accumulated damage and deficient clearance and replacement of senescent cells results in their accumulation, and consequently deleterious effects on tissue homeostasis that contributes to ageing. Reproduced from [13] with permission from the publisher. 
remove and degrade misfolded, unfolded or damaged proteins by the proteasome or the lysosome [48]. Cytosolic and organelle-specific chaperones are involved in protein folding and stability. Proteins damaged, for example as a result of free radical activity, need to be repaired or removed and replaced by functional proteins. The two principal proteolytic systems involved in degrading and removing damaged proteins are the autophagy-lysosomal system and the ubiquitin-proteosome system. Both of these systems have been shown to decline with age $[49,50]$. Thus the normal protein turnover is impaired with age, which can lead to the accumulation of altered proteins that contribute to the physiopathology of a number of age-related conditions.

\section{Inflammation}

There is an increase in low-grade systemic inflammation characterised by higher levels of circulating proinflammatory cytokines, such as interleukin (IL)-1 $\beta$, IL-6, IL- 8 and TNF- $\alpha$, in elderly people, which may contribute to several age-related disorders [51,52]. This has led to the inflamm-ageing hypothesis [53] as a common biological factor responsible for the decline and onset of disease in the elderly [54].

Inflamm-ageing may result from a variety of causes, such as the accumulation of pro-inflammatory tissue damage, failure of a dysfunctional immune system to effectively clear pathogens and dysfunctional host cells, the pro-inflammatory effect of senescent cells, enhanced activation of the pro-inflammatory transcription factor NF- $\mathrm{KB}$ or a defective autophagy response [55].

Other mechanisms involved in ageing include: 1) stem cell exhaustion as a result of multiple age associated damage, which reduces the regenerative potential of tissues; 2) dysregulated nutrient sensing; and 3) changes in anabolic signalling, particularly involving the insulin and insulin-like growth hormone, insulin-like growth factor-1 [56].

\section{Pulmonary effects of ageing}

Lung function deteriorates progressively with age [57]. As a result, elderly people have increased risk of developing shortness of breath and there is an increased prevalence of various pulmonary diseases in older individuals [58]. To more accurately establish an underlying respiratory disease, the reduction in pulmonary function must be distinguished from the reduction that is due to normal ageing [59]. Aged lungs are characterised by a progressive reduction of the forced expiratory volume in $1 \mathrm{~s}(\mathrm{FEV} 1)$ of $\sim 20 \mathrm{~mL} \cdot$ year $^{-1}$, together with a reduction of the $\mathrm{FEV} 1 /$ forced vital capacity ratio and an increment in the residual volume (RV), with preserved total lung capacity [60]. The changes in the ageing lung also result in lower oxygen levels and decreased ability to eliminate carbon dioxide, due to decreases in chest wall compliance, lung elastic recoil [61], respiratory muscle strength [62, 63] and also alveolar enlargement (without alveolar wall destruction), resulting in a decrease in the area for gas exchange in the lungs.

\section{Ageing and COPD}

Similarities between features of COPD and the ageing lung suggest that COPD may be a condition related to accelerated ageing [64]. Moreover, animal models of premature ageing show structural changes in the lungs and skeletal muscle that resemble those in COPD [65]. As shown by FLETCHER and PETO [57] in their classic epidemiological studies, an accelerated decline in lung function with age (50-100 mL of FEV1 per year) occurs in susceptible smokers who develop COPD. However, recent studies have shown that there is individual variability in the decline in FEV1 in COPD subjects and that the development of chronic airflow limitation, characteristic of COPD, is not always as a result of an accelerated decline in FEV1 [66], but can be due, for example, to sub-optimal lung growth in childhood [67]. This suggests that accelerated lung ageing may be a pathogenic mechanism in some but not all COPD subjects.

Similarly, RV is increased and respiratory muscle strength is also decreased in patients with COPD [68], as occurs with ageing. Furthermore, there is a good correlation between facial wrinkling, a feature of ageing, and emphysema [69]. The latter is probably due to changes in collagen and elastin degradation in both the skin and the lungs. Moreover, elastin degradation in the skin is related to emphysema and arterial stiffness in patients with COPD [70], providing a link between skin ageing, COPD and cardiovascular risk.

It has been proposed that a decline in organ function (such as the lung) is a feature of ageing in response to the accumulation of molecular and cell damage until the balance between cell death and cell replication (regeneration) is affected by the "intrinsic biological clock", which regulates the number of cell divisions. Therefore, any noxious exposure that increases cellular damage has the potential to accelerate the process of ageing in a particular organ. Thus, noxious inhalants, such as cigarette smoke, accelerate these age-related events in the lung due to increased modification of proteins, reduction in anti-ageing molecules and/or stimulation of pro-ageing molecules [71]. 
Increased oxidative stress, which is thought to play a key role in ageing [72] and the pathogenesis of COPD [73], is present in the lungs, blood and muscle in COPD patients. In the muscle it has been shown that mitochondria dysfunction results in increased release of ROS and oxidative damage to mitochondrial DNA $[74,75]$. Oxidative stress can lead to shortening of telomeres and shortened telomeres have been described in current and former smokers compared with nonsmokers, probably due to increased oxidative stress from the inhalation of cigarette smoke. There is also a dose-dependent relationship between telomere length and pack-years smoked [76]. Moreover, circulating leukocytes from COPD patients have shorter telomeres, compared with control subjects in any age range [77]. Parenchymal lung cells from emphysematous lungs also show shortened telomeres and this is associated with increased cell senescence [78]. These events may enhance lung inflammation [79], since telomere shortening leads to cellular senescence and, as a consequence, enhanced inflammation in these lungs [42]. Exposure of human epithelial cells to cigarette smoke, the major aetiological factor in COPD, results in cell senescence as shown by an increase in the senescent markers senescence-associated $\beta$-galactosidase and p21 protein [80]. Increased markers of cell senescence have been found in type II epithelial cells and fibroblasts from emphysematous lungs [79, 81] that contribute to the pathogenesis of COPD. Epithelial and endothelial apoptosis occurs in emphysema $[82,83]$ and is thought to result in loss of cells from the alveolar walls. Cellular senescence results in the loss of cell proliferation to replace cells lost by apoptosis. Senescent cells show activation of NF- $\kappa B$ and consequently release of inflammatory cytokines, thus enhancing inflammation [41]. A direct relationship has been shown between the extent of p16 ${ }^{\text {ink4a }}$ positive cell senescence and the severity of inflammation in emphysematous lungs [78].

Cigarette smoking has also been shown to suppress sirtuin expression in the large airways and, moreover, COPD is characterised by suppression of sirtuin expression both in large and small airway epithelial cells as a result of post-translational oxidative modification of the molecule that would result in enhanced inflammation and cell senescence [84].

In addition to sirtuins, HDAC2 has been shown to be an anti-ageing molecule since knockdown of HDAC2 induces cellular senescence [45]. HDAC2 has been shown to be reduced in the lungs of COPD patients compared with smokers who have not developed the disease [85] due to oxidative modification of the molecule [86]. This would lead to both increased cell senescence and enhanced inflammation as a result of increased histone acetylation and consequent unwinding of DNA, allowing enhanced pro-inflammatory gene expression $[87,88]$. Other features of premature ageing that have been described in patients with COPD are summarised in table 1.

\section{Extrapulmonary effects of ageing}

Although predominantly a lung disease, COPD is associated with significant extrapulmonary manifestations [109]. These extrapulmonary manifestations are very prevalent in COPD patients and contribute to the overall morbidity and mortality in this condition [110]. Many of these extrapulmonary manifestations are considered to be comorbidities of COPD. However, whether these co-existing conditions occur by chance or because they share risk factors (such as smoking), or occur as a consequence of the lung disease is unknown. Ageing may be a factor that links COPD to its extrapulmonary manifestations and it has been suggested that COPD should be considered as one of the multimorbidities related to ageing [8].

We will now discuss the major extrapulmonary effects of COPD (cardiovascular disease, skeletal muscle dysfunction and osteoporosis) in relation to ageing.

\section{Cardiovascular effects of ageing}

With increasing age the prevalence of cardiovascular disease increases several fold, and is the leading cause of death in people aged $\geqslant 65$ years. More than $80 \%$ of coronary artery disease cases and $>75 \%$ of congestive heart failure cases occur in people aged $>65$ years [111]. Thus, understanding the changes that occur in the cardiovascular system with advancing age may provide insight into the pathogenic mechanisms in cardiovascular disease and the relationship to COPD [112].

Ageing is associated with several molecular, biophysical and biochemical changes in the heart [113, 114]. The predominant change that occurs in the cardiovascular system with ageing is a reduction in elasticity of the vasculature and consequently increased arterial stiffness [112, 115]. This results from increased elastolytic activity in the vascular wall leading to elastin degradation and increased smooth muscle tone. These effects are particularly important in the large vessels such as the aorta, which demonstrates reduced compliance with ageing. This increased vascular stiffening leads to an increased afterload on the left ventricle, increased systolic blood pressure and changes in the left ventricular wall including hypertrophy. A further consequence of these changes is to lengthen the relaxation time of the left ventricle in diastole 
TABLE 1 Mechanisms of ageing in the pathogenesis of chronic obstructive pulmonary disease (COPD)

Mechanism

Oxidative stress

Telomere length

Tissue-specific cellular
senescence

Inflammatory cytokines

Neutrophils

Macrophages/monocytes

Dendritic cells

T-cells

B-cells
Ageing

COPD
Neutrophils, macrophages and monocytes show enhanced ROS production $[89,90]$

Telomere shortening is enhanced by oxidative stress [33, 93]

Decreased telomere length in peripheral blood leukocytes [94]

Induced when a critical telomere length is reached [96]

Persistent low-level inflammation: IL-6, TNF- $\alpha$ and acute-phase reactants [97]

Unchanged numbers and impaired killing [100]

Deficient TLR signalling, less production of pro-inflammatory cytokines [90, 101, 102]

Changed phenotype, increased levels of pro-inflammatory cytokines $[103,104]$

The proportion of memory cells that are CD28 null (senescent phenotype) increases and decreases the numbers of naïve T-cells [106]

Decreased B-cell production and impaired ability to undergo immunoglobulin class switch [108]
Increased oxidative stress in the lungs promoting inflammation $[74,75,91,92]$

Telomere length is smoking dose-dependent; telomere length is shorter in peripheral blood leukocytes in COPD and emphysema [76, 77, 93, 95]

Elevated SA- $\beta$-Gal, p21 $1^{\text {CIP1/WAP1/sdi1 }}$ and pro-inflammatory cytokine production in lung parenchyma and type II alveolar cells $[78,80]$

Increased systemic and pulmonary levels of IL-6, TNF- $\alpha$ and CRP $[98,99]$

Increased in BALF and lung parenchyma [100]

Increased in airways and lung parenchyma, and production of pro-inflammatory cytokines [100] More active in COPD [105]

Senescent T-cell phenotype and repertoire contraction [107]; less ability to fight infections

ROS: reactive oxygen species; SA- $\beta$-Gal: senescence-associated $\beta$-galactosidase; IL: interleukin; TNF: tumour necrosis factor; CRP: C-reactive protein; BALF: bronchoalveolar lavage fluid; TLR: Toll-like receptor.

thereby leading to diastolic dysfunction. Figure 5 summarises the cardiovascular consequences of arterial stiffening during ageing and the possible pathological implications of this process.

Ageing also changes the cardiac responsiveness to physiological and pharmacological $\beta$-adrenergic stimuli. The heart rate and myocardial contractility responses to both catecholamines and exercise are blunted in elderly subjects [116]. This is also a consequence of an age-related reduction in the inherent activity of the atrial pacemaker cells, leading to a decrease in the intrinsic heart rate [112]. In addition, there is increased fibrosis of the myocardium along with a decrease in the number and change in morphology of the cardiomyocytes [117]. Associated with these changes there is calcification at the base of the aortic valve and damage to the His bundle. All of these changes lead to a reduction in cardiac output, which is, to some extent, maintained by the ageing heart as a result of a marked increase in both end-diastolic and end-systolic ventricular volumes [117]. This in turn can lead to delayed relaxation as a result of heightened duration of contraction (negative lusiotropic effect) and consequently can precipitate diastolic dysfunction and heart failure as can occur in elderly individuals $[117,118]$.

A decrease in early diastolic filling rate occurs in the elderly resulting from a prolonged contraction time, but is also caused by a protracted relaxation time between aortic valve closure and mitral valve opening. This may be an effect of a reduction in the rate of calcium sequestration from the myoplasm to the sarcoplasmic reticulum [119].

\section{Cellular changes}

The cardiac myocytes are reduced in number and become elongated in shape with ageing $[120,121]$. This is associated with enhanced expression in the cardiac myocytes of molecules such as atrial natriuretic peptide (ANP) and growth factors such as angiotensin II $[122,123]$. This leads to a decay in myosin calcium ATPase activity, resulting in a change in intracellular calcium homeostasis and consequent prolonged contractibility of the cardiac muscles and possibly diastolic dysfunction.

In spite of the decrease in the early diastolic filling phase with age, the preload is still maintained to some extent because of forceful atrial contraction in late diastole [120, 122]. This dependence of the aged heart on atrial systole for ventricular filling increases the risk of developing heart failure when atrial fibrillation is present, since atrial contractility is lost. Exercise training can reverse the effect of ageing on cardiac 


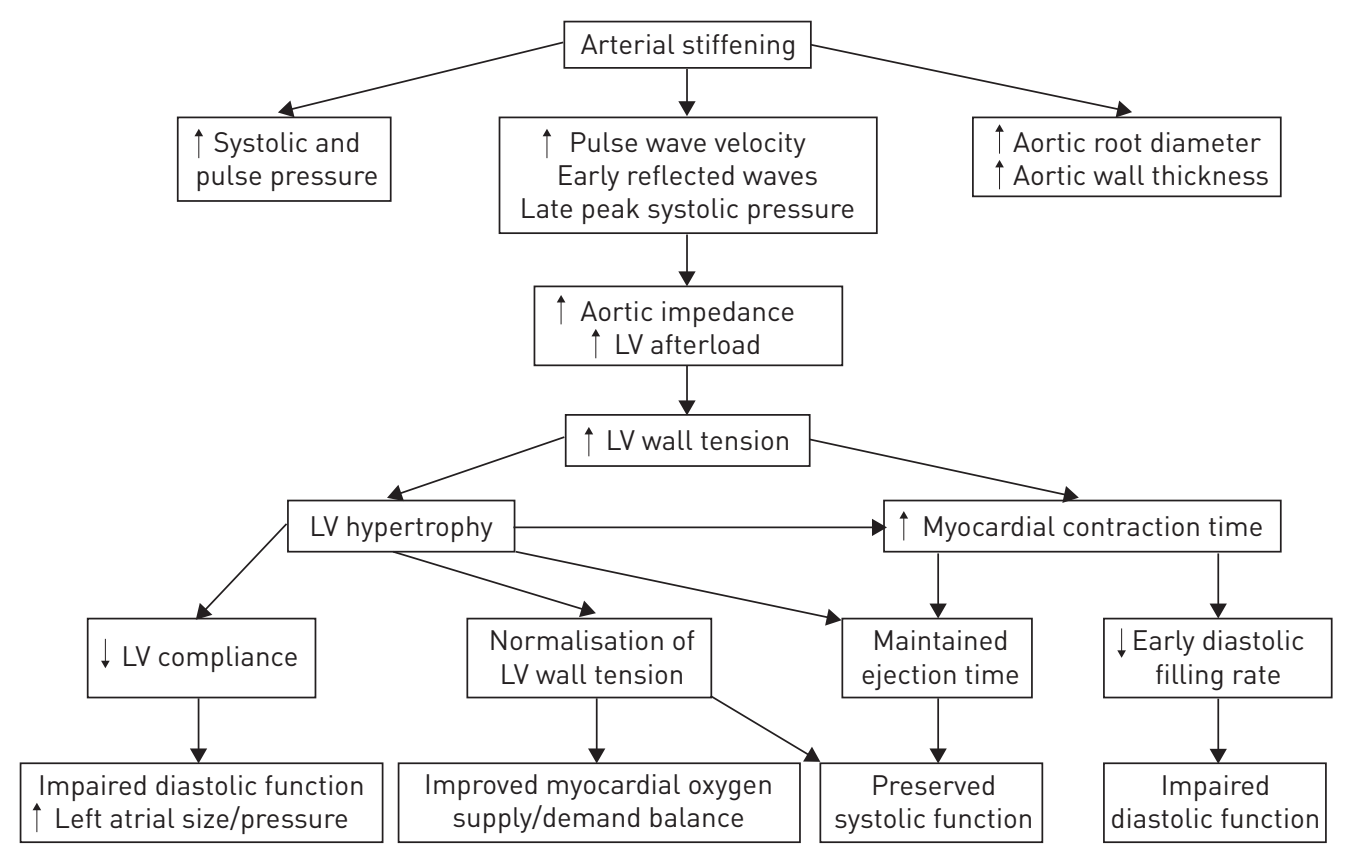

FIGURE 5 Cardiovascular changes with age. LV: left ventricular. Reproduced from [114] with permission from the publisher.

contractility and on the function of the sarcoplasmic reticulum, but not on the prolonged action potential and altered myosin isoform expression [124].

\section{Changes in baroreflex sensitivity}

One of the primary roles of the baroreflex is to prevent wide fluctuations in arterial blood pressure and to conserve the physiological cardiovascular homeostasis under basal resting conditions in reaction to acute stress $[125,126]$. Compared with younger subjects, older subjects show attenuated potentiation of the pressor responses, indicating that ageing is associated with impaired baroreflex buffering [127].

Arterial baroreceptors are stretch receptors that are predominantly present in the wall of the carotid sinus and in the aortic arch. These receptors and the associated nerve endings are sensitive to mechanical distortion of the vessel wall and change their rate of firing with changes in transmural pressure. Several factors, including circulating catecholamines, endothelial-dependent mediators and neural nitric oxide release, can modulate baroreceptor responses at the peripheral level by increasing or decreasing the sensitivity of the arterial baroreceptors [126].

Multiple studies have shown an age-related decline in the chronotropic activity of the heart is predominantly due to increased arterial stiffness [117, 128]. This dampened cardiovagal baroreflex sensitivity is a risk factor for life-threatening arrhythmias and is a predictor of sudden cardiac death [128-130]. With age there is also diminished respiratory sinus arrhythmia suggesting diminished parasympathetic activity on the sinus node activity [114, 131]. In addition, there are increased concentrations of circulating catecholamine with age, associated with increases in the basal rate of sympathetic neural firing $[117,132]$, all suggesting an increase in sympathetic activity.

Thus age-related impairment of the arterial baroreflex may alter the sympathovagal homeostasis of the heart. This has a multitude of clinical implications in elderly individuals, as reduced vagal control of the heart relates to increased cardiac and cerebrovascular mortality, independent of the classical risk factors $[130,133]$. This is of clinical importance as various studies have demonstrated the role of exercise, particularly aerobic exercise of moderate intensity, as a potent stimulus to attenuate the age-associated decline in cardiovagal baroreflex sensitivity [130, 134].

\section{Vascular changes}

With increasing age there is predominant thickening of the vessel media and intima [135]. Intimal thickening is characterised by irregular and elongated endothelial cells and proliferation of vascular smooth muscle cells, which is associated with elastin degradation and infiltration of the sub-endothelial space with 
collagen, proteoglycans and inflammatory leukocytes. Several pro-inflammatory and atherogenic mediators, such as adhesion molecules, matrix metalloproteinases, transforming growth factor- $\beta$, metalloproteinase- 2 , intercellular adhesion molecule and pro-inflammatory cytokines, have been implicated in these processes $[117,136]$. Transforming growth factor- $\beta$ release activates tissue inhibitors of metalloproteinase reducing protease activity and resulting in the accumulation of matrix proteins, leading to fibrosis of the intimal wall [137]. The collagen content in the media is increased together with increased calcium and cholesterol deposition in the elastin fibres, leading to further enhanced elastase activity, with progressive ageing [138]. This results in reduced glycoprotein content in elastin, making it more susceptible to degradation [138].

As discussed previously, age-associated increase in intimal thickening is accompanied by luminal dilatation, vascular stiffening and endothelial dysfunction [139]. Table 2 summarises the effects observed and associated with increased arterial stiffness [144].

As indicated previously, increased arterial stiffness contributes to the increase in systolic blood pressure and an initial levelling off of the diastolic blood pressure, followed by a decrease in diastolic blood pressure around 60-65 years of age. This further enhances the risk of isolated systolic hypertension and an elevated pulse pressure, both of which are associated with increased risk of cardiovascular events [141, 145]. The morphological changes, linked to arterial stiffness and arteriosclerosis, are measurable as the carotidfemoral pulse wave velocity and thus may be a noninvasive biomarker of increased cardiovascular risk [146, 147]. The Framingham Heart study confirmed that the prevalence of increased arterial stiffness, as measured by an elevated carotid-femoral pulse wave velocity $\left(\geqslant 12 \mathrm{~m} \cdot \mathrm{s}^{-1}\right)$ increases from $<5 \%$ before 50 years of age to $\geqslant 60 \%$ over 70 years of age, and is associated with increased risk of developing hypertension and cardiovascular events $[145,148]$.

Cardiovascular disease is highly prevalent in COPD patients and is a major cause of morbidity and mortality $[110,149,150]$. Although smoking is a common risk factor for both COPD and cardiovascular disease, COPD appears to be a risk factor for cardiovascular disease independent of smoking. Thus, atherosclerotic burden, as measured by carotid intimal medial thickness [151] or coronary artery calcification [152], is significantly greater in COPD patients compared with age-matched smokers without COPD.

Some of the changes in the cardiovascular system that occur with age are present in COPD patients. COPD patients have increased arterial stiffness compared with age-, sex- and smoking-matched control subjects $[153,154]$ and arterial stiffness in COPD patients is associated with increased systemic inflammation $[153,155]$ and the extent of emphysema [156]. Elastin degradation in the vessel wall may be the mechanism for the increased arterial stiffness that occurs with ageing and in COPD [70, 157].

Increased systemic inflammation that occurs with age is also present in a proportion of COPD patients $[158,159]$ and is associated with an increased risk of cardiovascular disease $[98,158]$ and mortality $[158,160]$.

Endothelial cellular senescence is believed to play a role in endothelial dysfunction and atherogenesis [159]. Shortened telomere length has been associated with increased arterial stiffness [161] and is a predictor of future acute coronary events [162]. Thus, mechanisms leading to accelerated ageing in the lungs and in the vasculature may provide a mechanistic link between COPD and its associated vascular dysfunction.

\section{Ageing and the bones}

Advanced age is a well-established risk factor for osteoporosis [163]. During the process of ageing significant amounts of bone are lost. This is due to increased bone resorption and decreased bone formation that is opposite to the normal turnover of bone occurring in a healthy young skeleton, in which the rate of bone resorption and matrix degradation is matched by bone formation and matrix mineralisation.

Bone remodelling is controlled by several mechanisms such as the osteoprotegerin/receptor activator of NF$\mathrm{kB}$ (RANK)/RANK ligand (RANKL) system. RANKL expression on the surface of osteoblasts increases in response to a variety of pro-resorptive signals, such as parathyroid hormone and inflammatory cytokines. RANKL binds to the RANK receptor, expressed on osteoclasts and their precursors, stimulating the differentiation and activation of osteoclasts and promoting bone resorption.

TABLE 2 Vascular implications of increased arterial stiffness

Enhanced blood pressure variability and associated increased cardiovascular mortality [140]

Compromised baroreceptor function, leading to orthostatic hypotension and increased cardiovascular mortality [141]

Diminished endothelial function associated with reduced vasodilation and increased macrovascular complications [87, 142]

Reduced heart rate variability associated with increased cardiovascular mortality $[88,143]$ 
Osteoporosis is a condition characterised by bone fragility and increased risk of fracture [164] due to low bone mineral density or micro-architectural deterioration. It is diagnosed by a dual energy X-ray absorptiometry scan based on the lowest T-score (number of standard deviations from the average bone mineral density of a young adult) of the hip or the lumbar spine. A T-score $\leqslant-2.5$ defines osteoporosis while a score between -1.0 to -2.5 defines osteopenia. A score $\geqslant-1.0$ is considered to be representative of a normal bone mass. The main risk factors for osteoporosis are advanced age, smoking, low body weight and physical inactivity, among others [164, 165].

The underlying pathophysiology of bone loss in advanced age has been widely studied [166]. Several factors seem to be involved, including decreased levels of sexual hormones and insulin-like growth factor-1 and nutrition lacking minerals, as well as a side-effect of drugs, particularly corticosteroids [166]. Moreover, ageing affects the formation of the active form of vitamin $\mathrm{D}$ which, in turn, affects the adequate absorption of calcium [167-169].

Similarly to the aged population, the prevalence of osteoporosis is high in patients with COPD in comparison to healthy age-matched control subjects [168]. 23\% of the 658 patients included in the TORCH (Towards a Revolution in COPD Health) study had osteoporosis, while 43\% had osteopenia [169]. When taking vertebral fractures into account, the prevalence of osteoporosis is even greater (51\%) [170]. Osteoporosis-related fractures may contribute to the morbidity and mortality of COPD patients, as vertebral compression fractures in these patients further reduce the already compromised pulmonary function by $4 \%$ to $8 \%[171,172]$. Thus, osteoporosis impacts health status and prognosis in COPD patients. In turn, fractures in patients with COPD have ominous prognostic implications [173].

Many of the risk factors for osteoporosis in the general population are features of COPD including advanced age, smoking, low physical activity levels, and low body weight. Thus the prevalence of osteoporosis is higher in patients with COPD and low body mass index [174] and the same is true of sarcopenia, the main cause of weight loss in COPD, suggesting a common factor for these two extrapulmonary manifestations of COPD [175].

Reduced physical activity, a common feature of COPD [176] is a common pathogenic mechanism for muscle wasting and osteoporosis [177]. Moreover, there is evidence supporting an endocrine loop connecting muscle and bone [178, 179]. Specific factors such as vitamin D deficiency, systemic inflammation, oxidative stress, the use of corticosteroids and lung function impairment may contribute to increase the risk of osteoporosis in COPD.

Markers of systemic inflammation, that are elevated in COPD patients [180, 181], are also observed in many or the systemic manifestations of COPD, such as cardiovascular disease, muscle wasting and osteoporosis, providing evidence that systemic inflammation is the possible the common link between them [182]. Bone density in COPD is also related to the extent of emphysema [183] and to both arterial stiffness [153] and coronary artery calcification [184] as markers of cardiovascular disease, suggesting a common link between these extrapulmonary manifestations of COPD that may be ageing.

Malnutrition caused by inflammation and hormonal changes have been postulated as mechanisms involved in the pathogenesis of osteoporosis in chronic inflammatory diseases [185]. In turn, nutrition deficiency, physical inactivity and the use of corticosteroids have been related to osteoporosis in COPD [186-189]. High concentrations of TNF- $\alpha$ have been associated with osteopenia, independent of the use of corticosteroids [190]. TNF- $\alpha$ and other T-cell cytokines such as IL-1 and IL-6 may induce the expression of RANKL, leading to osteoporosis [191]. Free radical damage, a key component of tissue degeneration associated with ageing, has also been related to the pathogenesis of osteoporosis [192].

\section{Skeletal muscle}

Age-related decrement in muscle performance is associated with physical impairment and is explained by the loss of muscle mass (sarcopenia) and a reduction in muscle strength (dynapenia). Therefore, two different but related phenomena occur with age: 1) the loss of muscle bulk, and 2) an impairment of the quality of the skeletal muscle. Thus, skeletal muscle function deficit is the term that better describes the impairment in muscle performance associated with age [193]. Reduced muscle function is an independent predictor of disability, hospitalisation and mortality [194]. Sarcopenia was first defined as an age-related phenomenon in 1989 by Rosenberg [195]. The loss of muscle bulk associated with age is now well established [196, 197].

No definition of sarcopenia has been universally accepted. A widely use definition of sarcopenia is the loss of relative muscle mass, measured by dual-energy X-ray absorbptiometry, divided by the square of height expressed in meters that is below two standard deviations of the normal population aged 18-40 years [198]. JANSSEN et al. [199] proposed a definition of sarcopenia that included a classification of its severity, based on 
the skeletal muscle index, calculated by dividing the total muscle mass obtained by bioimpedance by the total body mass. Normal muscle mass was therefore defined as being within one standard deviation of the healthy population, while class I and class II sarcopenia were defined as between one and two standard deviations and more than two standard deviations, respectively [200]. More recently it has been recognised that the term should describe not only changes in body composition but also in muscle function, and it has been proposed that the diagnosis of sarcopenia requires both loss of muscle bulk and loss of muscle strength or muscle performance [198]. This approach is based in the fact that loss of muscle mass alone is not associated with limitations in activity, but that concomitant loss of muscle strength is necessary to explain limitations in activity [201].

The incidence of sarcopenia is reported to occur in $15 \%$ of males and $24 \%$ of females aged $65-70$ years, increasing to $50 \%$ in both sexes aged $>80$ years [202]. Although sarcopenia is common in the elderly, there is some variation in the prevalence in different populations [202,203]. The median loss of muscle mass in relation to age is $0.47 \%$ and $0.37 \%$ per year in males and females, respectively [204]. Interestingly the rate of loss is not uniform across muscle groups, being almost twice as rapid in the lower limb, compared with the upper limb muscles [205].

Muscle strength is the most common way to assess muscle function and is part of the practical clinical definition and consensus diagnostic criteria for age-related sarcopenia [198]. Muscle strength can be evaluated as the maximum strength against an immovable object (isometric strength) or against an object that moves through an arc at a fixed angular speed (isokinetic peak torque strength). The power of the muscle describes the rate of energy transferred, and is the product of the speed and force of contraction. These aspects of muscle function can be measured in a concentric (within a shortening muscle that acts against a load which it overcomes) or eccentric (when the muscle is actively lengthened by external forces) manner. The fatigability describes the reduction of the ability to exert muscle strength or power after fatiguing stimuli such as exercise [204].

While isometric and concentric strength are reduced in the elderly population and are associated with mortality [206], eccentric strength seems to be preserved in the elderly and other conditions associated with muscle loss and weakness [207]. As with muscle mass, loss of strength is more pronounced with age in the lower than in the upper limbs [205]. Isometric strength [208] and power [209] are also impaired in this population, while fatigability seems to be relatively preserved in elderly [210].

These alterations in muscle bulk and function, which are characteristic of ageing, are associated with several morphological changes described in the muscle of the elderly population. There is a decrease in cross sectional area of the muscle that is observed in vastus lateralis biopsies, which is partially explained by a loss of muscle fibres with no particular preference of fibre type. However, the size of type II fibres is significantly reduced while the diameter of type I fibres is preserved [204]. There is also an increase in the percentage of hybrid fibres (those expressing two myosin heavy chain isoforms concomitantly), such as myosin heavy chain I/IIA and IIA/IIx [211]. However, there is controversy regarding changes in fibre type distribution with some studies showing a shift towards slow myosin isoforms [212] and others failing to reproduce these findings [213].

An alteration of the capillary density [214] and ratio of capillary/fibres [215] has also been shown to be altered in the elderly population. This suggests an impairment of the availability of oxygen in the microcirculation of the muscle.

The mechanisms underlying the skeletal muscle dysfunction that are characteristic of ageing are multifactorial. To achieve proteostasis, a close match between protein synthesis and breakdown is required. In the fasted state at rest, $0.05 \%$ of the myofibrillar mass is synthesised each hour and there is no difference between young and older subjects. However, the synthesis rate during either feeding or exercise, which doubles in youth, seems to be blunted in the elderly [216]. Moreover, the insulin-related suppression of proteolysis is diminished in older people in comparison to a young population [217].

Interestingly, the number of satellite cells, the pluripotential cells of the muscle responsible for muscle regeneration, is reduced by $37 \%$ and $24 \%$ in elderly males and females, respectively, which may lead to a loss of regeneration capacity of the muscle associated with age [218]. In turn, the loss of limb motor neurons characteristic of the elderly suggests that denervation significantly contributes to muscle wasting in this population [219].

If loss of muscle mass is related to an imbalance between protein synthesis and breakdown in favour of the latter, the loss of muscle quality suggests a change in the profile of protein synthesis. Several proteins show a differential expression when comparing elderly with young subjects [212]. Most of the enzymes that are 
downregulated belong to the anaerobic metabolism, while enzymes participating in the aerobic metabolism are upregulated.

Several hormonal changes associated with ageing have been found in ageing-related sarcopenia, namely menopause [220] and andropause [221], decreased levels of dehydroepiandrosterone [222], decreased activity of pituitary growth hormone [220] and high parathyroid hormone levels [223]. Chronic inflammation and elevated cytokine levels, which are characteristic of ageing, have been related to the skeletal muscle function deficit. IL-6 levels are related to quadriceps strength in healthy older people [224]. TNF- $\alpha$, a markedly catabolic and pro-apoptotic cytokine, has also been shown to be elevated in the elderly population [225]. Consistent with a role of low grade inflammation within aged muscles is the increased expression of genes such as FOXO3A, galectin-1 and C1AQ, which are involved in apoptosis signalling [226]. Furthermore, there is a reduction in the antioxidant capacity and an increase in the generation of ROS due to dysfunction of the mitochondrial respiratory chain that results in increased oxidative stress in the elderly muscle [227].

Similar to the parallelism between changes in the ageing lung and COPD, elderly subjects and patients with COPD both exhibit skeletal muscle dysfunction characterised by alterations in muscle quality and loss of muscle mass. Muscle mass loss is present in $18-36 \%$ of patients with COPD [228, 229], while weight loss is evident in $17-35 \%$ of COPD patients depending on the population studied [228-232]. Muscle wasting can occur in patients with preserved weight [229]. Moreover, muscle loss relates to muscle strength [233-235] and exercise tolerance [229, 236-238], independent of the degree of airway obstruction [238]. Muscle wasting is a better indicator of body cell mass depletion than body weight [229]. Recent longitudinal studies have shown that changes in muscle bulk are not different when comparing patients with COPD and agematched healthy controls (both smokers and never-smokers) [239, 240]. However, in the study by VAN DEN BORST et al. [239], COPD patients showed lower muscle mass in comparison to smoking controls, suggesting a common insult earlier in life related to smoking. It is of note that loss of muscle bulk takes place in phases in COPD and is not necessarily a continuous process. When present, muscle wasting is associated with worse prognosis [240]. Muscle bulk decline is associated with several factors such as frequent exacerbations and air trapping [241].

Pathophysiological findings responsible for the malfunction of the muscle have been described in the peripheral muscles of patients with COPD and are as follows: 1) fibre type re-distribution [242]; 2) alteration in muscle bioenergetics [243]; and 3) alteration in muscle capillarisation [244, 245].

Despite the relevance of skeletal muscle dysfunction in COPD, the pathogenic mechanisms of this phenomenon remain unclear. Several potential mechanisms have been related to peripheral muscle dysfunction/wasting in patients with COPD. Factors considered relevant to the skeletal muscle dysfunction include: 1) protein synthesis/breakdown balance [246, 247]; 2) nutritional abnormalities [248]; 3) muscle disuse [176]; 4) systemic corticosteroids [249]; 5) tissue hypoxia and hypercapnia [250]; 6) alterations in muscle remodelling [251]; 7) inflammation [252]; 8) oxidative/nitrosative stress [253]; and 9) mitochondrial abnormalities [254]. Thus, there are several similarities between the pathophysiological and pathogenic mechanisms of muscle abnormalities in COPD and ageing. Interestingly, it has recently been shown that limb muscles of patients with COPD have increased number of senescent satellite cells and an exhausted muscle regenerative capacity, compromising the maintenance of muscle mass in these individuals [255]. Thus, suggesting that premature cellular senescence and subsequent exhaustion of the regenerative potential of the muscles can explain, at least in part, the peripheral muscle abnormalities characteristic of these patients.

\section{Potential treatment for ageing}

Increasing understanding of the mechanisms of ageing may provide new targets for the treatment of conditions thought to be associated with accelerated ageing, such as COPD. A range of drugs termed "geroprotectors"" have been identified in reducing oxidative stress, cell senescence and subsequent chronic inflammation (table 3) [256].

Drugs that activate nuclear factor erythroid 2-related factor 2, a redox-sensitive transcription factor that induces endogenous anti-oxidant molecules, such as sulforaphane, have been shown to reverse the nitrosylation of HDAC2 that occurs in COPD and may, therefore, have an anti-inflammatory and antiageing effect $[257,258]$.

Restoring normal sirtuin activity by sirtuin activators could have a role in autophagy and DNA repair, and in reducing inflammation and oxidative stress; thus, preventing premature senescence. Resveratrol, a plant polyphenol found in various plants and red wine, has been shown to activate SIRT1 [256]. Other more 
TABLE 3 Potential geroprotectors and their modes of action

Sulforaphane
Resveratol
Metformin
Melatonin
Rapamycin
Low-dose theophylline

Nrf2: nuclear factor erythroid 2-related factor2; AMPK: AMP-activated protein kinase; PI3K: phosphatidylinositide 3-kinases; mTOR: mammalian target of rapamycin.

potent selective SIRT1 activators have been shown to be effective in reducing smoking-induced inflammation [259].

Metformin, which is commonly used to treat type 2 diabetes, can also slow the rate of ageing. Metformin activates AMP-activated protein kinase thus enhancing the sirtuin-FOXO axis, resulting in extension of life span [260].

Melatonin, a controller of circadian rhythms, is a potent scavenger of ROS and is known to increase lifespan in animals [256]. In a study in COPD patients, melatonin was shown to reduce markers of oxidative stress, with improvements in dyspnoea, without any significant changes in lung function [261].

Phosphoinositide 3-kinase (PI3K) $\delta$ has been shown to be upregulated in the peripheral lung of COPD patients and is thought to be involved in corticos-teroid resistance [262]. PI3K inhibition has been shown to extend life span in animal models [263]. PI3K $\delta$ inhibitors are not available for clinical use; however, lowdose theophylline is known to produce functional PI3K $\delta$ inhibition. Theophylline has been shown to reverse the defect in HDAC activity in COPD via PI3K $\delta$ inhibition [262]. Since HDAC2 is thought to be an anti-ageing molecule, theophylline could be considered as an anti-ageing agent.

Mammalian target of rapamycin (mTOR) is a serine/threonine kinase in the PI3K-related kinase family that forms two distinct complexes; TORC1 and TORC 2. TORC1 regulates cell cycle progression, mitochondrial biogenesis and autophagy [264]. Therefore, inhibition of mTOR results in geroprotection. Rapamycin, an immunosuppressive agent, inhibits TORC1 and has been shown to extend the life span of mice [264], but has not been studied in COPD.

In order to counteract the negative effects of senescence in elderly individuals, stem cell therapies are now being investigated as a potential approach [265]. Recently, a randomised, placebo-controlled trial of mesenchymal stem cells therapy of moderate-to-severe COPD was shown to be safe, but failed to show any clinical improvement [266]. However, regenerative therapies remain a potential therapy for chronic diseases associated with ageing.

Besides pharmacological interventions that can potentially have an effect on ageing through different mechanisms, exercise is the only non-pharmacological intervention associated with an anti-ageing effect. Exercise training (and physical activity) is capable of reversing some of the effects of ageing, such as loss of muscle mass or function, by promoting the expression of myofibrillar proteins. Regular exercise is associated with maintaining longer telomeres [267]. Moreover, exercise improves glucose metabolism and increases insulin sensitivity [268]. Specifically in COPD, exercise training increase exercise capacity by improving muscle function and mass, which contributes to an increase in health-related quality of life and a reduction in the risk of exacerbations and hospitalisations [269].

\section{Conclusions}

Ageing is among the most important known risk factor for most chronic conditions and results from a range of intrinsic phenomena that affects the whole organism. There are many similarities between the ageing process in the lungs and COPD and its common systemic consequences and comorbidities.

This suggests that premature ageing may constitute a pathogenic mechanism contributing to COPD. Understanding the mechanisms of ageing may provide a novel target for the treatment of this condition.

\section{References}

Kirkwood TB. Understanding the odd science of aging. Cell 2005; 120: 437-447.

World Health Organization. Ageing and Life Course. Care and independence in older age. www.who.int/ageing/en Date last accessed: August 2014. 
Dillin A, Gottschling DE, Nystrom T. The good and the bad of being connected: the integrons of aging. Curr Opin Cell Biol 2014; 26: 107-112.

4 De Grey ADNJ. Life span extension research and public debate: societal considerations. Studies Ethics Law Technol $2007 ; 1$.

Harris RE, ed. Epidemiology of Chronic Diease Global Perspectives. Massachusetts, Jones and Bartlett Learning, 2013. Spence AP, ed. Biology of Human Aging. 2nd Edn. Englewood Cliffs, Prentice Hall, 1995.

Hayflick L. Entropy explains aging, genetic determinism explains longevity, and undefined terminology explains misunderstanding both. PLoS Genet 2007; 3: e220.

8 Agusti A. Phenotypes and disease characterization in chronic obstructive pulmonary disease. Ann Am Thorac Soc 2013; 10: Suppl., S125-S130.

9 MacNee W. Accelerated lung aging: a novel pathogenic mechanism of chronic obstructive pulmonary disease (COPD). Biochem Soc Trans 2009; 37: 819-823.

10 Dodds C. Physiology of ageing. Anaesth Intensive Care Med 2006; 7: 456-458.

11 Knight J, Nigam Y. Exploring the anatomy and physiology of ageing. Part 1: the cardiovascular system. Nurs Times 2008; 104: 26-27.

Martin P, Poon LW, Hagberg B. Behavioral factors of longevity. J Aging Res 2011; 2011: 197590.

Lopez-Otin C, Blasco MA, Partridge L, et al. The hallmarks of aging. Cell 2013; 153: 1194-1217.

14 Tuder RM, Yoshida T, Fijalkowka I, et al. Role of lung maintenance program in the heterogeneity of lung destruction in emphysema. Proc Am Thorac Soc 2006; 3: 673-679.

15 Gems D, Partridge L. Genetics of longevity in model organisms: debates and paradigm shifts. Annu Rev Physiol 2013; 75: 621-644.

16 Vijg J, Campisi J. Puzzles, promises and a cure for ageing. Nature 2008; 454: 1065-1071.

17 Campisi J, Kim SH, Lim CS, et al. Cellular senescence, cancer and aging: the telomere connection. Exp Gerontol 2001; 36: 1619-1637.

18 Mereschcowski K. Theorie der zwei Plasmaarten als Grundlage der Symbiogenesis, einer neuen Lehre von der Entstehung der Organismen [The theory of two plasmas as the basis of symbiogenesis, a New Study or the Origins of Organisms]. Biol Centralbl 1910; 30: 353-367.

19 Sagan L. On the origin of mitosing cells. J Theor Biol 1967; 14: 255-274.

20 Balaban RS, Nemoto S, Finkel T. Mitochondria, oxidants, and aging. Cell 2005; 120: 483-495.

21 Liu Y, Fiskum G, Schubert D. Generation of reactive oxygen species by the mitochondrial electron transport chain. J Neurochem 2002; 80: 780-787.

22 Harman D. Aging: a theory based on free radical and radiation chemistry. J Gerontol 1956; 11: 298-300.

23 Bratic A, Larsson NG. The role of mitochondria in aging. J Clin Invest 2013; 123: 951-957.

24 Harman D. Free radical theory of aging: an update: increasing the functional life span. Ann N Y Acad Sci 2006; 1067: 10-21.

25 Speakman JR, Selman C. The free-radical damage theory: accumulating evidence against the simple link of oxidative stress to ageing and life span. Bioessays 2011; 33: 255-259.

26 Liochev SI. Reflections on the theories of aging, of oxidative stress, and of science in general. Is it time to abandon the free radical (oxidative stress) theory of aging? Antioxid Redox Signal 2014 [In press DOI: 10.1089/ ars.2014.5928].

( Hekimi S, Lapointe J, Wen Y. Taking a "good" look at free radicals in the aging process. Trends Cell Biol 2011; 21: 569-576.

29 Barja G. The mitochondrial free radical theory of aging. Prog Mol Biol Transl Sci 2014; 127: 1-27.

30 Rahman I, Adcock IM. Oxidative stress and redox regulation of lung inflammation in COPD. Eur Respir J 2006; 28: 219-242.

Krabbe KS, Pedersen M, Bruunsgaard H. Inflammatory mediators in the elderly. Exp Gerontol 2004; 39: 687-699. Hayflick L. The limited in vitro lifetime of human diploid cell strains. Exp Cell Res 1965; 37: 614-636.

Saretzki G, Von Zglinicki T. Replicative aging, telomeres and oxidative stress. Ann N Y Acad Sci 2002; 959: 24-29. Chan SR, Blackburn EH. Telomeres and telomerase. Philos Trans R Soc Lond B Biol Sci 2004; 359: $109-121$.

Boonekamp JJ, Simons MJ, Hemerik L, et al. Telomere length behaves as biomarker of somatic redundancy rather than biological age. Aging Cell 2013; 12: 330-332.

36 Kuilman T, Michaloglou C, Mooi WJ, et al. The essence of senescence. Genes Dev 2010; $24: 2463-2479$.

37 Bodnar AG, Ouellette M, Frolkis M, et al. Extension of life-span by introduction of telomerase into normal human cells. Science 1998; 279: 349-352.

38 Lombard DB, Chua KF, Mostoslavsky R, et al. DNA repair, genome stability, and aging. Cell 2005 ; 120 : 497-512. Collado M, Blasco MA, Serrano M. Cellular senescence in cancer and aging. Cell 2007; 130: $223-233$.

40 Campisi J. Senescent cells, tumour suppression, organismal aging: good citizens, bad neighbours. Cell 2005; 120: 513-522.

41 Shelton DN, Chang E, Whittier PS, et al. Microarray analysis of replicative senescence. Curr Biol 1999; 9: 939-945.

42 Amsellem V, Gary-Bobo G, Marcos E, et al. Telomere dysfunction causes sustained inflammation in chronic obstructive pulmonary disease. Am J Respir Crit Med 2011; 184: 1358-1366.

43 Bitterman KJ, Anderson RM, Cohen HY, et al. Inhibition of silencing and accelerated aging by nicotinamide, a putative negative regulator of yeast sir2 and human SIRT1. J Biol Chem 2002; 277: 45099-45107.

44 Beauharnois JM, Bolivar BE, Welch JT. Sirtuin 6: a review of biological effects and potential therapeutic properties. Mol Biosyst 2013; 9: 1789-1806.

45 Harms KL, Chen X. Histone deacetylase 2 modulates p53 transcriptional activities through regulation of p53-DNA binding activity. Cancer Res 2007; 67: 3145-3152.

46 Espejel S, Franco S, Sgura A, et al. Functional interaction between DNA-PKcs and telomerase in telomere length maintenance. EMBO J 2002; 21: 6275-6287.

47 Powers ET, Morimoto RI, Dillin A, et al. Biological and chemical approaches to diseases of proteostasis deficiency. Annu Rev Biochem 2009; 78: 959-991.

48 Hartl FU, Bracher A, Hayer-Hartl M. Molecular chaperones in protein folding and proteostasis. Nature 2011; 475: $324-332$. 
49 Calderwood SK, Murshid A, Prince T. The shock of aging: molecular chaperones and the heat shock response in longevity and aging - a mini-review. Gerontology 2009; 55: 550-558.

50 Rubinsztein DC, Mariño G, Kroemer G. Autophagy and aging. Cell 2011; 146: 682-695.

51 Franceschi C, Bonafe M, Valensin S, et al. Inflamm-aging. An evolutionary perspective on immunosenescence. Ann N Y Acad Sci 2000; 908: 244-254.

52 Bruunsgaard H, Pedersen M, Pedersen BK. Aging and proinflammatory cytokines. Curr Opin Hematol 2001; 8: 131-136.

53 De Martinis M, Francheschi C, Monti D, et al. Inflamm-ageing and lifelong antigenic load as major determinants of ageing rate and longevity. FEBS Lett 2005; 579: 2035-2039.

54 Cevenini E, Monti D, Franceschi C. Inflamm-ageing. Curr Opin Clin Nutr Metab Care 2013; 16: 14-20.

55 Salminen A, Kaarniranta K, Kauppinen A. Inflammaging: disturbed interplay between autophagy and inflammasomes. Aging (Albany NY) 2012; 4: 166-175.

56 Fontana L, Partridge L, Longo VD. Extending healthy life span - from yeast to humans. Science 2010; 328: 321-326.

57 Fletcher C, Peto R. The natural history of chronic airflow obstruction. Br Med J 1977; 1: 1645-1648.

58 Akgun KA, Crothers K, Pisani M. Epidemiology and management of common pulmonary disease in older persons. J Gerontol A Biol Sci Med Sci 2012; 67: 276-291.

59 Vaz Fragoso CA, Gill TM. Respiratory impairment and the aging lung: a novel paradigm for assessing pulmonary function. J Gerontol A Biol Sci Med Sci 2012; 67: 264-275.

60 Chan ED, Welsh CH. Geriatric respiratory medicine. Chest 1998; 114: 1704-1733.

61 Janssens JP. Aging of the respiratory system: impact on pulmonary function tests and adaptation to exertion. Clin Chest Med 2005; 26: 469-484

62 Tolep K, Kelsen SG. Effect of aging on respiratory skeletal muscles. Clin Chest Med 1993; 14: 363-378.

63 Polkey MI, Harris ML, Hughes PD, et al. The contractile properties of the elderly human diaphragm. Am J Respir Crit Care Med 1997; 155: 1560-1564.

64 Ito K, Mercado N. STOP accelerating lung aging for the treatment of COPD. Exp Gerontol 2014 [In press DOI: 10.1016/j.exger.2014.03.014].

65 Kuro-o M, Matsumura Y, Aizawa H, et al. Mutation of the mouse klotho gene leads to a syndrome resembling ageing. Nature 1997; 390: 45-51.

66 Vestbo J, Edwards LD, Scanlon PD, et al. Changes in forced expiratory volume in 1 second over time in COPD. N Engl J Med 2011; 365: 1184-1192.

67 Sanchez-Salcedo P, Divo M, Casanova C, et al. Disease progression in young patients with COPD: rethinking the Fletcher and Peto model. Eur Respir J 2014; 44: 324-331.

68 Stubbings AK, Moore AJ, Dusmet M, et al. Physiological properties of human diaphragm muscle fibres and the effect of chronic obstructive pulmonary disease. J Physiol 2008; 586: 2637-2650.

69 Patel BD, Loo WJ, Tasker AD, et al. Smoking related COPD and facial wrinkling: is there a common susceptibility? Thorax 2006; 61: 568-571.

70 Maclay JD, McAllister DA, Rabinovich R, et al. Systemic elastin degradation in chronic obstructive pulmonary disease. Thorax 2012; 67: 606-612.

71 Ito K, Barnes PJ. COPD as a disease of accelerated lung aging. Chest 2009; 135: 173-180.

72 Schöttker B, Saum KU, Jansen EH, et al. Oxidative stress markers and all-cause mortality at older age: a population-based cohort study. J Gerontol A Biol Sci Med Sci 2014 [In press DOI: 10.1093/gerona/glu111].

73 MacNee W, Rahman I. Is oxidative stress central to the pathogenesis of chronic obstructive pulmonary disease? Trends Mol Med 2001; 7: 55-62.

74 Puente-Maestu L, Perez-Parra J, Godoy R, et al. Abnormal transition pore kinetics and cytochrome c release in muscle mitochondria of patients with chronic obstructive pulmonary disease. Am J Respir Cell Mol Biol 2009; 40: 746-750.

75 Puente-Maestu L, Perez-Parra J, Godoy R, et al. Abnormal mitochondrial function in locomotor and respiratory muscles of COPD patients. Eur Respir J 2009; 33: 1045-1052.

76 Morla M, Busquets X, Pons J, et al. Telomere shortening in smokers with and without COPD. Eur Respir J 2006; 27: 525-528.

77 Valdes AM, Andrew T, Gardner JP, et al. Obesity, cigarette smoking, and telomere length in women. Lancet 2005; 366: 662-624.

78 Tsuji T, Aoshiba K, Nagai A. Alveolar cell senescence in patients with pulmonary emphysema. Am J Respir Crit Care Med 2006; 174: 886-893.

79 Tsuji T, Aoshiba K, Nagai A. Alveolar cell senescence exacerbates pulmonary inflammation in patients with chronic obstructive pulmonary disease. Respiration 2010; 80: 59-70.

80 Tsuji T, Aoshiba K, Nagai A. Cigarette smoke induces senescence in alveolar epithelial cells. Am J Respir Cell Mol Biol 2004; 31: 643-649.

81 Nyunoya T, Monick MM, Klingelhutz A, et al. Cigarette smoke induces cellular senescence. Am J Respir Cell Mol Biol 2006; 35: 681-688.

82 Yokohori N, Aoshiba K, Nagai A. Increased levels of cell death and proliferation in alveolar wall cells in patients with pulmonary emphysema. Chest 2004; 125: 626-632.

83 Kasahara Y, Tuder RM, Cool CD, et al. Endothelial cell death and decreased expression of vascular endothelial growth factor and vascular endothelial growth factor receptor 2 in emphysema. Am J Respir Crit Care Med 2001; 163: 737-744.

84 Rajendrasozhan S, Yang SR, Kinnula VL, et al. SIRT1, an antiinflammatory and antiaging protein, is decreased in lungs of patients with chronic obstructive pulmonary disease. Am J Respir Crit Care Med 2008; 177: 861-701.

85 Szulakowski P, Crowther AJ, Jimenez LA, et al. The effect of smoking on the transcriptional regulation of lung inflammation in patients with chronic obstructive pulmonary disease. Am J Respir Crit Care Med 2006; 174: 41-50.

86 Ito K, Ito M, Elliott WM, et al. Decreased histone deacetylase activity in chronic obstructive pulmonary disease. N Engl J Med 2005; 352: 1967-1976.

87 Ocker M, Schneider-Stock R. Histone deacetylase inhibitors: signalling towards p21cip1/waf1. Int J Biochem Cel Biol 2007; 39: 1367-1374. 
88 Royce SG, Karagiannis TC. Histone deacetylases and their inhibitors: new implications for asthma and chronic respiratory conditions. Curr Opin Allergy Clin Immunol 2014; 14: 44-48.

89 Beerman I, Bhattacharya D, Zandi S, et al. Functionally distinct hematopoietic stem cells modulate hematopoietic lineage potential during aging by a mechanism of clonal expansion. Proc Natl Acad Sci USA 2010; 107: 5465-5470.

90 Shaw AC, Joshi S, Greenwood H, et al. Aging of the innate immune system. Curr Opin Immunol 2010; 22: 507-513.

91 MacNee W. Pulmonary and systemic oxidant/antioxidant imbalance in chronic obstructive pulmonary disease. Proc Am Thorac Soc 2005; 2: 50-60.

92 MacNee W, Tuder RM. New paradigms in the pathogenesis of chronic obstructive pulmonary disease. Proc Am Thorac Soc 2009; 6: 527-531.

93 Alder JK, Guo N, Kembou F, et al. Telomere length is a determinant of emphysema susceptibility. Am J Respir Crit Care Med 2011; 184: 904-912.

94 Kaszubowska L. Telomere shortening and ageing of the immune system. J Physiol Pharmacol 2008; 59: 169-186.

95 Savale L, Chaouat A, Bastuji-Garin S, et al. Shortened telomeres in circulating leukocytes of patients with chronic obstructive pulmonary disease. Am J Respir Crit Care Med 2009; 179: 566-571.

96 Aviv A. Telomeres and human aging: facts and fibs. Sci Aging Knowledge Environ 2004; 2004: pe43.

97 Franceschi C, Capri M, Monti D, et al. Inflammaging and anti-inflammaging: a systemic perspective on aging and longevity emerged from studies in humans. Mech Ageing Dev 2007; 128: 92-105.

98 Agusti A. Systemic effects of chronic obstructive pulmonary disease: what we know and what we don't know (but should). Proc Am Thorac Soc 2007; 4: 522-525.

99 Rabe KF, Hurd S, Anzueto A, et al. Global Initiative for Chronic Obstructive Lung Disease. Global strategy for the diagnosis, management, and prevention of chronic obstructive pulmonary disease: GOLD executive summary. Am J Respir Crit Care Med 2007; 176: 532-555.

100 Galgani M, Fabozzi I, Perna F, et al. Imbalance of circulating dendritic cell subsets in chronic obstructive pulmonary disease. Clin Immunol 2010; 137: 102-110.

101 Della BS, Bierti L, Presicce P, et al. Peripheral blood dendritic cells and monocytes are differently regulated in the elderly. Clin Immunol 2007; 122: 220-228.

102 Shaw AC, Panda A, Joshi SR, et al. Dysregulation of human Toll-like receptor function in aging. Ageing Res Rev 2011; 10: 346-353.

103 Agrawal A, Gupta S. Impact of aging on dendritic cell functions in humans. Ageing Res Rev 2011; 10: 336-345.

104 Panda A, Qian F, Mohanty S, et al. Age-associated decrease in TLR function in primary human dendritic cells predicts influenza vaccine response. J Immunol 2010; 184: 2518-2527.

105 Givi ME, Redegeld FA, Folkerts G, et al. Dendritic cells in pathogenesis of COPD. Curr Pharm Des 2012; 18: 2329-2335.

106 Lynch HE, Goldberg GL, Chidgey A, et al. Thymic involution and immune reconstitution. Trends Immunol 2009; 30: $366-373$.

107 Lambers C, Hacker S, Posch M, et al. T cell senescence and contraction of T cell repertoire diversity in patients with chronic obstructive pulmonary disease. Clin Exp Immunol 2009; 155: 466-475.

108 Frasca D, Diaz A, Romero M, et al. Age effects on B cells and humoral immunity in humans. Ageing Res Rev 2011; 10: $330-335$.

109 Choudhury G, Rabinovich R, MacNee W. Comorbidities and systemic effects of chronic obstructive pulmonary disease. Clin Chest Med 2014; 35: 101-130.

110 Miller J, Edwards LD, Agustí A, et al. Evaluation of COPD Longitudinally to Identify Predictive Surrogate Endpoints (ECLIPSE) Investigators. Comorbidity, systemic inflammation and outcomes in the ECLIPSE cohort. Respir Med 2013; 107: 1376-1384.

111 Rosamond W, Flegal K, Furie K, et al. American Heart Association Statistics Committee and Stroke Statistics Subcommittee. Heart disease and stroke statistics - 2008 update: a report from the American Heart Association Statistics Committee and Stroke Statistics Subcommittee. Circulation 2008; 117: e25-e146.

112 Cheitlin MD. Cardiovascular physiology-changes with aging. Am J Geriatr Cardiol 2003; 12: 9-13.

113 Folkow B, Svanborg A. Physiology of cardiovascular aging. Physiol Rev 1993; 73: 725-764.

114 Priebe HJ. The aged cardiovascular risk patient. Br J Anaesth 2000; 85: 763-778.

115 Vaitkevicius PV, Fleg JL, Engel JH, et al. Effects of age and aerobic capacity on arterial stiffness in healthy adults. Circulation 1993; 88: 1456-1462.

116 Fleg JL, O'Connor FC, Gerstenblith G, et al. Impact of age on the cardiovascular response to dynamic upright exercise in healthy men and women. J Appl Physiol 1995; 78: 890-900.

117 Ferrari AU, Radaelli A, Centola M. Aging and the cardiovascular system. J Appl Physiol 2003; 95: 2591-2597.

118 Lakatta EG, Gerstenblith G, Angell CS, et al. Prolonged contraction duration in aged myocardium. J Clin Invest 1975; 55: 61-68.

119 Lakatta EG. Cardiovascular aging research: the next horizons. J Am Geriatr Soc 1999; 47: 613-625.

120 Ali Raza J, Movahed A. Use of cardiovascular medications in the elderly. Int J Cardiol 2002; 85: 203-215.

121 Kajstura J, Cheng W, Sarangarajan R, et al. Necrotic and apoptotic myocyte cell death in the aging heart of Fischer 344 rats. Am I Physiol 1996; 271: H1215-H1228.

122 Esler MD, Turner AG, Kaye DM, et al. Aging effects on human sympathetic neuronal function. Am J Physiol 1995; 268: R278-285.

123 Cigola E, Kajstura J, Li B, et al. Angiotensin II activates programmed myocyte cell death in vitro. Exp Cell Res 1997; 231: 363-371.

124 Carneiro-Júnior MA, Prímola-Gomes TN, Quintão-Júnior JF, et al. Regional effects of low-intensity endurance training on structural and mechanical properties of rat ventricular myocytes. J Appl Physiol (1985) 2013; 115: 107-115.

125 Eckberg DL, Sleight P, eds. Human Baroreflexes in Health and Disease. Oxford, Clarendon Press, 1992.

126 La Rovere MT, Pinna GD. Beneficial effects of physical activity on baroreflex control in the elderly. Ann Noninvasive Electrocardiol 2014; 19: 303-310.

127 Jones PP, Christou DD, Jordan J, et al. Baroreflex buffering is reduced with age in healthy men. Circulation 2003; 107: 1770-1774.

128 Okada Y, Galbreath MM, Shibata S, et al. Relationship between sympathetic baroreflex sensitivity and arterial stiffness in elderly men and women. Hypertension 2012; 59: 98-104. 
129 Billman GE, Schwartz PJ, Stone HL. Baroreceptor reflex control of heart rate: a predictor of sudden cardiac death. Circulation 1982; 66: 874-880.

130 La Rovere MT, Pinna GD, Hohnloser SH, et al. Baroreflex sensitivity and heart rate variability in the identification of patients at risk for life-threatening arrhythmias: implications for clinical trials. Circulation 2001; 103: 2072-2077.

131 Klein AL, Leung DY, Murray RD, et al. Effects of age and physiologic variables on right ventricular filling dynamics in normal subjects. Am J Cardiol 1999; 84: 440-448.

132 Ebert TJ, Morgan BJ, Barney JA, et al. Effects of aging on baroreflex regulation of sympathetic activity in humans. Am J Physiol 1992; 263: H798-H803.

133 Huikuri HV, Mäkikallio TH, Airaksinen KE, et al. Power-law relationship of heart rate variability as a predictor of mortality in the elderly. Circulation 1998; 97: 2031-2036.

134 Okazaki K, Iwasaki K, Prasad A, et al. Dose-response relationship of endurance training for autonomic circulatory control in healthy seniors. J Appl Physiol 2005; 99: 1041-1049.

135 Virmani R, Avolio AP, Mergner WJ, et al. Effect of aging on aortic morphology in populations with high and low prevalence of hypertension and atherosclerosis: comparison between occidental and Chinese communities. Am J Pathol 1991; 139: 1119-1129.

$136 \mathrm{Li} \mathrm{Z,} \mathrm{Froehlich} \mathrm{J,} \mathrm{Galis} \mathrm{ZS,} \mathrm{et} \mathrm{al.} \mathrm{Increased} \mathrm{expression} \mathrm{of} \mathrm{matrix} \mathrm{metalloproteinase-2} \mathrm{in} \mathrm{the} \mathrm{thickened} \mathrm{intima} \mathrm{of} \mathrm{aged}$ rats. Hypertension 1999; 33: 116-123.

137 Border WA, Ruoslahti E. Transforming growth factor-beta in disease: the dark side of tissue repair. J Clin Invest 1992; 90: 1-7.

138 Robert L. Aging of the vascular wall and atherogenesis: role of the elastini-laminin receptor. Atherosclerosis 1996; 123: $169-179$.

139 Lakatta EG. Arterial and cardiac aging: major shareholders in cardiovascular disease enterprises. Part III: cellular and molecular clues to heart and arterial aging. Circulation 2003; 107: 490-497.

140 Rothwell PM, Howard SC, Dolan E, et al. Prognostic significance of visit-to-visit variability, maximum systolic blood pressure, and episodic hypertension. Lancet 2010; 375: 895-905.

141 Mattace-Raso FU, van den Meiracker AH, Bos WJ, et al. Arterial stiffness, cardiovagal baroreflex sensitivity and postural blood pressure changes in older adults: the Rotterdam Study. J Hypertens 2007; 25: 1421-1426.

142 Nemes A, Csanády M, Forster T. Does increased aortic stiffness predict reduced coronary flow velocity reserve in patients with suspected coronary artery disease? Acta Physiol Hung 2012; 99: 271-278.

143 Theilade S, Lajer M, Persson F, et al. Arterial stiffness is associated with cardiovascular, renal, retinal, and autonomic disease in type 1 diabetes. Diabetes Care 2013; 36: 715-721.

144 Nilsson PM. Hemodynamic aging as the consequence of structural changes associated with early vascular aging (EVA). Aging Dis 2014; 5: 109-113.

145 Franklin SS, Lopez VA, Wong ND, et al. Single versus combined blood pressure components and risk for cardiovascular disease: the Framingham Heart Study. Circulation 2009; 119: 243-250.

146 Mitchell GF, Parise H, Benjamin EJ, et al. Changes in arterial stiffness and wave reflection with advancing age in healthy men and women: the Framingham Heart Study. Hypertension 2004; 43: 1239-1245.

147 Nilsson PM, Boutouyrie P, Cunha P, et al. Early vascular ageing in translation: from laboratory investigations to clinical applications in cardiovascular prevention. J Hypertens 2013; 8: 1517-1526.

148 Birru MS, Matthews KA, Thurston RC, et al. African-American ethnicity and cardiovascular risk factors are related to aortic pulse-wave velocity progression. Am J Hypertens 2011; 24: 809-815.

149 Mapel DW, Dedrick D, Davis K. Trends and cardiovascular co-morbidities of COPD patients in the Veterans Administration Medical System, 1991-1999. COPD 2005; 2: 35-41.

150 Anthonisen NR, Connett JE, Enright PL, et al. Hospitalizations and mortality in the Lung Health Study. Am J Respir Crit Care Med 2002; 166: 333-339.

151 Iwamoto H, Yokoyama A, Kitahara $\mathrm{Y}$, et al. Airflow limitation in smokers is associated with subclinical atherosclerosis. Am J Respir Crit Care Med 2009; 179: 35-40.

152 Williams MC, Murchison JT, Edwards LD, et al. Coronary artery calcification is increased in patients with COPD and associated with increased morbidity and mortality. Thorax 2014; 69: 718-723.

153 Sabit R, Bolton CE, Edwards PH, et al. Arterial stiffness and osteoporosis in chronic obstructive pulmonary disease. Am J Respir Crit Care Med 2007; 175: 1259-1265.

154 McAllister DA, Maclay JD, Mills NL, et al. Vascular dysfunction in chronic obstructive pulmonary disease. Am J Respir Crit Care Med 2009; 180: 513-520.

155 Mills NL, Miller JJ, Anand A, et al. Increased arterial stiffness in patients with chronic obstructive pulmonary disease: a mechanism for increased cardiovascular risk. Thorax 2008; 63: 306-311.

156 McAllister DA, Maclay JD, Mills NL, et al. Arterial stiffness is independently associated with emphysema severity in patients with chronic obstructive pulmonary disease. Am J Respir Crit Care Med 2007; 176: 1208-1214.

157 Maclay J, MacNee W. Cardiovascular disease in COPD: mechanisms. Chest 2014; 143: 798-807.

158 Agustí A, Edwards LD, Rennard SI, et al. Persistent systemic inflammation is associated with poor clinical outcomes in COPD: a novel phenotype. PLoS One 2012; 7: e37483.

159 Minamino T, Miyauchi H, Yoshida T, et al. Endothelial cell senescence in human atherosclerosis: role of telomere in endothelial dysfunction. Circulation 2002; 105: 1541-1544.

160 Celli BR, Locantore N, Yates J, et al. Inflammatory biomarkers improve clinical prediction of mortality in chronic obstructive pulmonary disease. Am J Respir Crit Care Med 2012; 185: 1065-1072.

161 Benetos A, Okuda K, Lajemi M, et al. Telomere length as an indicator of biological aging: the gender effect and relation with pulse pressure and pulse wave velocity. Hypertension 2001; 37: 381-385.

162 Brouilette SW, Moore JS, McMahon AD, et al. Telomere length, risk of coronary heart disease, and statin treatment in the West of Scotland Primary Prevention Study: a nested case-control study. Lancet 2007; 369: 107-114.

163 Papaioannou A, Kennedy CC, Cranney A, et al. Risk factors for low BMD in healthy men age 50 years or older: a systematic review. Osteoporosis Int 2009; 20: 507-518.

164 Waugh EJ, Lam MA, Hawker GA, et al. Risk factors for low bone mass in healthy 40-60 year old women: a systematic review of the literature. Osteoporosis Int 2009; 20: 1-21.

165 Syed FA, Ng AC. The pathophysiology of the aging skeleton. Curr Osteoporos Rep 2010; 8: 235-240.

166 Banu J. Causes, consequences, and treatment of osteoporosis in men. Drug Des Devel Ther 2013; 7: 849-860. 
167 Gallagher JC. Vitamin D and aging. Endocrinol Metab Clin North Am 2013; 42: 319-332.

168 Bolton CE, Ionescu AA, Shiels KM, et al. Associated loss of fat-free mass and bone mineral density in chronic obstructive pulmonary disease. Am J Respir Crit Care Med 2004; 170: 1286-1293.

169 Ferguson GT, Calverley PM, Anderson JA, et al. Prevalence and progression of osteoporosis in patients with COPD: results from the TOwards a Revolution in COPD Health study. Chest 2009; 136: 1456-1465.

170 Graat-Verboom L, van den Borne BE, Smeenk FW, et al. Osteoporosis in COPD outpatients based on bone mineral density and vertebral fractures. J Bone Miner Res 2011; 26: 561-568.

171 Lehouck A, Boonen S, Decramer M, et al. COPD, bone metabolism, and osteoporosis. Chest 2011; 139: 648-657.

172 Leech JA, Dulberg C, Kellie S, et al. Relationship of lung function to severity of osteoporosis in women. Am Rev Respir Dis 1990; 141: 68-71.

173 de Luise C, Brimacombe M, Pedersen L, et al. Chronic obstructive pulmonary disease and mortality following hip fracture: a population-based cohort study. Eur J Epidemiol 2008; 23: 115-122.

174 Maggi S, Siviero P, Gonnelli S, et al. Osteoporosis risk in patients with chronic obstructive pulmonary disease: the EOLO study. J Clin Densitom 2009; 12: 3 45-52.

175 Coin A, Sergi G, Marin S, et al. Predictors of low bone mineral density in elderly males with chronic obstructive pulmonary disease: the role of body mass index. Aging Male 2010; 13: 142-147.

176 Pitta F, Troosters T, Spruit MA, et al. Characteristics of physical activities in daily life in chronic obstructive pulmonary disease. Am J Respir Crit Care Med 2005; 171: 972-977.

177 DiGirolamo DJ, Kiel DP, Esser KA. Bone and skeletal muscle: neighbors with close ties. J Bone Miner Res 2013; 28 : 1509-1518.

178 Yasui A, Nishizawa H, Okuno Y, et al. Foxo1 represses expression of musclin, a skeletal muscle-derived secretory factor. Biochem Biophys Res Commun 2007; 364: 358-365.

179 Moffatt P, Thomas GP. Osteocrin - beyond just another bone protein? Cell Mol Life Sci 2009; 66: 1135-1139.

180 Huertas A, Palange P. COPD: a multifactorial systemic disease. Ther Adv Respir Dis 2011; 5: 217-224.

181 MacNee W. Systemic inflammatory biomarkers and co-morbidities of chronic obstructive pulmonary disease. Ann Med 2013; 45: 291-300.

182 Barnes PJ, Celli BR. Systemic manifestations and comorbidities of COPD. Eur Respir J 2009; 33: 1165-1185.

183 Romme EA, Murchison JT, Edwards LD, et al. CT-measured attenuation in patients with chronic obstructive pulmonary disease: relation to clinical features and outcomes. J Bone Miner Res 2013; 28: 1369-1377.

184 Romme EA, McAllister DA, Murchison JT, et al. Associations between COPD related manifestations: a crosssectional study. Respir Res 2013; 14: 129.

185 Montalcini T, Romeo S, Ferro Y, et al. Osteoporosis in chronic inflammatory disease: the role of malnutrition. Endocrine 2013; 43: 59-64.

186 Incalzi RA, Caradonna P, Ranieri P, et al. Correlates of osteoporosis in chronic obstructive pulmonary disease. Respir Med 2000; 94: 1079-1084.

187 Shane E, Silverberg SJ, Donovan D, et al. Osteoporosis in lung transplantation candidates with end-stage pulmonary disease. Am J Med 1996; 101: 262-269.

188 Iqbal F, Michaelson J, Thaler L, et al. Declining bone mass in men with chronic pulmonary disease: contribution of glucocorticoid treatment, body mass index, and gonadal function. Chest 1999; 116: 1616-1624.

189 Sin DD, Man JP, Man SF. The risk of osteoporosis in Caucasian men and women with obstructive airways disease. Am J Med 2003; 114: 10-14.

190 Sevenoaks MJ, Stockley RA. Chronic obstructive pulmonary disease, inflammation and co-morbidity - a common inflammatory phenotype? Respir Res 2006; 7: 70.

191 Anandarajah AP, Schwarz EM. Anti-RANKL therapy for inflammatory bone disorders: Mechanisms and potential clinical applications. J Cell Biochem 2006; 97: 226-232.

192 Almeida M, O’Brien CA. Basic biology of skeletal aging: role of stress response pathways. J Gerontol A Biol Sci Med Sci 2013; 68: 1197-1208.

193 Correa-de-Araujo R, Hadley E. Skeletal muscle function deficit: a new terminology to embrace the evolving concepts of sarcopenia and age-related muscle dysfunction. J Gerontol A Biol Sci Med Sci 2014; 69: 591-594.

194 Newman AB, Kupelian V, Visser M, et al. Strength, but not muscle mass, is associated with mortality in the health, aging and body composition study cohort. J Gerentol A Biol Sci Med Sci 2006; 61: 72-77.

195 Rosenberg I. Summary comments: epidemiological and methodological problems in determining nutritional status of the older persons. Am J Clin Nutr 1989; 50: 1231-1233.

196 Narici MV, Maffulli N. Sarcopenia: characteristics, mechanisms and functional significance. Br Med Bull 2010; 95 : 139-159.

197 Cruz-Jentoft AJ, Baeyens JP, Bauer JM, et al. Sarcopenia: European consensus on definition and diagnosis: Report of the European Working Group on Sarcopenia in Older People. Age Ageing 2010; 39: 412-423.

198 Baumgartner RN, Koehler KM, Gallagher D, et al. Epidemiology of sarcopenia among the elderly in New Mexico. Am J Epidemiol 1998; 147: 755-763.

199 Janssen I, Heymsfield SB, Ross R. Low relative skeletal muscle mass (sarcopenia) in older persons is associated with functional impairment and physical disability. J Am Geriatr Soc 2002; 50: 889-896.

200 Delmonico MJ, Harris TB, Lee JS, et al. Alternative definitions of sarcopenia, lower extremity performance, and functional impairment with aging in older men and women. J Am Geriatr Soc 2007; 55: 769-774.

201 Tanko LB, Movsesyan L, Mouritzen U, et al. Appendicular lean tissue mass and the prevalence of sarcopenia among healthy women. Metabolism 2002; 51: 69-74.

202 Chien MY, Huang TY, Wu YT. Prevalence of sarcopenia estimated using a bioelectrical impedance analysis prediction equation in community-dwelling elderly people in Taiwan. J Am Geriatr Soc 2008; 56: 1710-1715.

203 Mitchell WK, Williams J, Atherton P, et al. Sarcopenia, dynapenia, and the impact of advancing age on human skeletal muscle size and strength; a quantitative review. Front Physiol 2012; 3: 260.

204 Janssen I, Heymsfield SB, Wang ZM, et al. Skeletal muscle mass and distribution in 468 men and women aged 18-88 yr. J Appl Physiol (1985) 2000; 89: 81-88.

205 Laukkanen P, Heikkinen E, Kauppinen M. Muscle strength and mobility as predictors of survival in 75-84-year-old people. Age Ageing 1995; 24: 468-473. 
206 Porter MM, Vandervoort AA, Kramer JF. Eccentric peak torque of the plantar and dorsiflexors is maintained in older women. J Gerontol A Biol Sci Med Sci 1997; 52: B125-B131.

207 Frontera WR, Hughes VA, Fielding RA, et al. Aging of skeletal muscle: a 12-yr longitudinal study. J Appl Physiol (1985) 2000; 88: 1321-1326.

208 Yu F, Hedstrom M, Cristea A, et al. Effects of ageing and gender on contractile properties in human skeletal muscle and single fibres. Acta Physiol (Oxf) 2007; 190: 229-241.

209 Macaluso A, De Vito G. Muscle strength, power and adaptations to resistance training in older people. Eur J Appl Physiol 2004; 91: 450-472.

210 Avin KG, Law LA. Age-related differences in muscle fatigue vary by contraction type: a meta-analysis. Phys Ther 2011; 91: 1153-1165.

211 Klitgaard H, Zhou M, Schiaffino S, et al. Ageing alters the myosin heavy chain composition of single fibres from human skeletal muscle. Acta Physiol Scand 1990; 140: 55-62.

212 Gelfi C, Vigano A, Ripamonti M, et al. The human muscle proteome in aging. J Proteome Res 2006; 5: 1344-1353.

213 Marx JO, Kraemer WJ, Nindl BC, et al. Effects of aging on human skeletal muscle myosin heavy-chain mRNA content and protein isoform expression. J Gerontol A Biol Sci Med Sci 2002; 57: B232-B238.

214 Coggan AR, Spina RJ, King DS, et al. Histochemical and enzymatic comparison of the gastrocnemius muscle of young and elderly men and women. J Gerontol 1992; 47: B71-B76.

215 Andersen JL. Muscle fibre type adaptation in the elderly human muscle. Scand J Med Sci Sports 2003; 13: 40-47.

216 Kumar V, Selby A, Rankin D, et al. Age-related differences in the dose-response relationship of muscle protein synthesis to resistance exercise in young and old men. J Physiol 2009; 587: 211-217.

217 Wilkes EA, Selby AL, Atherton PJ, et al. Blunting of insulin inhibition of proteolysis in legs of older subjects may contribute to age-related sarcopenia. Am J Clin Nutr 2009; 90: 1343-1350.

218 Kadi F, Charifi N, Denis C, et al. Satellite cells and myonuclei in young and elderly women and men. Muscle Nerve 2004; 29: 120-127.

219 Tomlinson BE, Irving D. The numbers of limb motor neurons in the human lumbosacral cord throughout life. J Neurol Sci 1977; 34: 213-219.

220 Lamberts SW, van den Beld AW, van der Lely AJ. The endocrinology of aging. Science 1997; 278: 419-424.

221 Urban RJ, Bodenburg YH, Gilkison C, et al. Testosterone administration to elderly men increases skeletal muscle strength and protein synthesis. Am J Physiol 1995; 269: E820-E826.

222 Ganong WF, ed. Review of Medical Physiology. New York, McGraw Hill, 2005.

223 Visser M, Deeg DJ, Lips P. Low vitamin D and high parathyroid hormone levels as determinants of loss of muscle strength and muscle mass (sarcopenia): the Longitudinal Aging Study Amsterdam. J Clin Endocrinol Metab 2003; 88: 5766-5772.

224 Yende S, Waterer GW, Tolley EA, et al. Inflammatory markers are associated with ventilatory limitation and muscle dysfunction in obstructive lung disease in well functioning elderly subjects. Thorax 2006; 61: 10-16.

225 Pedersen M, Bruunsgaard H, Weis N, et al. Circulating levels of TNF-alpha and IL-6-relation to truncal fat mass and muscle mass in healthy elderly individuals and in patients with type-2 diabetes. Mech Ageing Dev 2003; 124: 495-502.

226 Giresi PG, Stevenson EJ, Theilhaber J, et al. Identification of a molecular signature of sarcopenia. Physiol Genomics 2005; 21: 253-263.

227 Barreiro E, Coronell C, Lavina B, et al. Aging, sex differences, and oxidative stress in human respiratory and limb muscles. Free Radic Biol Med 2006; 41: 797-809.

228 Engelen MP, Schols AM, Baken WC, et al. Nutritional depletion in relation to respiratory and peripheral skeletal muscle function in out-patients with COPD. Eur Respir J 1994; 7: 1793-1797.

229 Schols AM, Soeters PB, Dingemans AM, et al. Prevalence and characteristics of nutritional depletion in patients with stable COPD eligible for pulmonary rehabilitation. Am Rev Respir Dis 1993; 147: 1151-1156.

230 Eid AA, Ionescu AA, Nixon LS, et al. Inflammatory response and body composition in chronic obstructive pulmonary disease. Am J Respir Crit Care Med 2001; 164: 1414-1418.

231 Braun SR, Keim NL, Dixon RM, et al. The prevalence and determinants of nutritional changes in chronic obstructive pulmonary disease. Chest 1984; 86: 558-563.

232 Gray-Donald K, Gibbons L, Shapiro SH, et al. Effect of nutritional status on exercise performance in patients with chronic obstructive pulmonary disease. Am Rev Respir Dis 1989; 140: 1544-1548.

233 Bernard S, Leblanc P, Whittom F, et al. Peripheral muscle weakness in patients with chronic obstructive pulmonary disease. Am J Respir Crit Care Med 1998; 158: 629-634.

234 Gosselink R, Troosters T, Decramer M. Peripheral muscle weakness contributes to exercise limitation in COPD. Am J Respir Crit Care Med 1996; 153: 976-980.

235 Engelen MP, Schols AM, Does JD, et al. Skeletal muscle weakness is associated with wasting of extremity fat-free mass but not with airflow obstruction in patients with chronic obstructive pulmonary disease. Am J Clin Nutr 2000; 71: 733-738.

236 Baarends EM, Schols AM, Mostert R, et al. Peak exercise response in relation to tissue depletion in patients with chronic obstructive pulmonary disease. Eur Respir J 1997; 10: 2807-2813.

237 Kobayashi A, Yoneda T, Yoshikawa M, et al. The relation of fat-free mass to maximum exercise performance in patients with chronic obstructive pulmonary disease. Lung 2000; 178: 119-127.

238 Schols AM, Mostert R, Soeters PB, et al. Body composition and exercise performance in patients with chronic obstructive pulmonary disease. Thorax 1991; 46: 695-699.

239 van den Borst B, Koster A, Yu B, et al. Is age-related decline in lean mass and physical function accelerated by obstructive lung disease or smoking? Thorax 2011; 66: 961-969.

240 Rutten EP, Calverley PM, Casaburi R, et al. Changes in body composition in patients with chronic obstructive pulmonary disease: do they influence patient-related outcomes? Ann Nutr Metab 2013; 63: 239-247.

241 Hopkinson NS, Tennant RC, Dayer MJ, et al. A prospective study of decline in fat free mass and skeletal muscle strength in chronic obstructive pulmonary disease. Respir Res 2007; 8: 25.

242 Maltais F, Sullivan MJ, Leblanc P, et al. Altered expression of myosin heavy chain in the vastus lateralis muscle in patients with COPD. Eur Respir J 1999; 13: 850-854. 
243 Maltais F, Leblanc $\mathrm{P}$, Whittom F, et al. Oxidative enzyme activities of the vastus lateralis muscle and the functional status in patients with COPD. Thorax 2000; 55: 848-853.

244 Simard C, Maltais F, Leblanc P, et al. Mitochondrial and capillarity changes in vastus lateralis muscle of COPD patients: Electron Microscopy Study. Med Sci Sports Exerc 1996; 28: S95.

245 Jobin J, Maltais F, Doyon JF, et al. Chronic obstructive pulmonary disease: capillarity and fiber characteristics of skeletal muscle. J Cardiopulm Rehabil 1998; 18: 432-437.

246 Morrison WL, Gibson J, Scrimegeour C, et al. Muscle wasting in emphysema. Clin Sci 1988; 75: 415-420.

247 Aguilaniu B, Goldstein-Shapses S, Pajon A, et al. Muscle protein degradation in severely malnourished patients with chronic obstructive pulmonary disease subject to short-term total parenteral nutrition. JPEN J Parenter Enteral Nutr 1992; 16: 248-254.

248 Wilson DO, Donahoe M, Rogers RM, et al. Metabolic rate and weight loss in chronic obstructive lung disease. J Parenter Enteral Nutr 1990; 14: 7-11.

249 Decramer M, De Bock V, Dom R. Functional and histologic picture of steroid-induced myopathy in chronic obstructive pulmonary disease. Am J Respir Crit Care Med 1996; 153: 1958-1964.

250 Preedy VR, Smith DM, Sugden PH. The effects of 6 hours of hypoxia on protein synthesis in rat tissues in vivo and in vitro. Biochem J 1985; 228: 179-185.

251 Crul T, Spruit MA, Gayan-Ramirez G, et al. Markers of inflammation and disuse in vastus lateralis of chronic obstructive pulmonary disease patients. Eur J Clin Invest 2007; 37: 897-904.

252 Rabinovich RA, Figueras M, Ardite E, et al. Increased tumour necrosis factor- $\alpha$ plasma levels during moderateintensity exercise in COPD patients. Eur Respir J 2003; 21: 789-794.

253 Rabinovich RA, Ardite E, Troosters T, et al. Reduced muscle redox capacity after endurance training in COPD patients. Am J Respir Crit Care Med 2001; 164: 1114-1118.

254 Rabinovich RA, Bastos R, Ardite E, et al. Mitochondrial dysfunction in COPD patients with low body mass index. Eur Respir J 2007; 29: 643-650.

255 Theriault ME, Pare ME, Maltais F, et al. Satellite cells senescence in limb muscle of severe patients with COPD. PloS One 2012; 7: e39124.

256 Ito K, Colley T, Mercado N. Geroprotectors as a novel therapeutic strategy for COPD, an accelerating aging disease. Int J Chron Obstruct Pulmon Dis 2012; 7: 641-652.

257 Malhotra D, Thimmulappa RK, Mercado N, et al. Denitrosylation of HDAC2 by targeting Nrf2 restores glucocorticosteroid sensitivity in macrophages from COPD patients. J Clin Invest 2011; 121: 4289-4302.

258 Sussan TE, Rangasamy T, Blake DJ, et al. Targeting Nrf2 with the triterpenoid CDDO-imidazolide attenuates cigarette smoke-induced emphysema and cardiac dysfunction in mice. Proc Natl Acad Sci USA 2009; 106: 250-255.

259 Yao H, Chung S, Hwang JW, et al. SIRT1 protects against emphysema via FOXO3-mediated reduction of premature senescence in mice. J Clin Invest 2012; 122: 2032-2045.

260 Bulterijs S. Metformin as a geroprotector. Rejuvenation Res 2011; 14: 469-482.

261 de Matos Cavalcante AG, de Bruin PF, de Bruin VM, et al. Melatonin reduces lung oxidative stress in patients with chronic obstructive pulmonary disease: a randomized, double-blind, placebo controlled study. J Pineal Res 2012; 53: $238-244$.

262 To Y, Ito K, Kizawa Y, et al. Targeting phosphoinositide-3-kinase- $\delta$ with theophylline reverses corticosteroid insensitivity COPD. Am J Respir Crit Care Med 2010; 182: 897-904.

263 Babar P, Adamson C, Walker GA, et al. P13-kinase inhibition induces dauer formation, thermotolerance and longevity in C. elegans. Neurobiol Aging 1999; 20: 513-519.

264 Bjedov I, Partridge L. A longer and healthier life with TOR down-regulation: genetics and drugs. Biochem Soc Trans 2011; 39: 460-465.

265 Beltrami AP, Cesselli D, Beltrami CA. Stem cell senescence and regenerative paradigms. Clin Pharmacol Ther 2012; 91: 21-29.

266 Weiss DJ, Casaburi R, Flannery R, et al. A placebo-controlled, randomized trial of mesenchymal stem cells in COPD. Chest 2013; 143: 1590-1598.

267 Melk A, Tegtbur U, Hilfiker-Kleiner D, et al. Improvement of biological age by physical activity. Int J Cardiol 2014 [In press DOI: 10.1016/j.ijcard.2014.07.236]

268 Heikkila HM, Krachler B, Rauramaa R, et al. Diet, insulin secretion and insulin sensitivity - the Dose-Responses to Exercise Training (DR's EXTRA) Study (ISRCTN45977199). Br J Nutr 2014; 18: 1-12.

269 Spruit MA, Singh SJ, Garvey C, et al. An official American Thoracic Society/European Respiratory Society statement: key concepts and advances in pulmonary rehabilitation. Am J Respir Crit Care Med 2013; 188: e13-e64. 